\title{
Characterization of Host Phases for Actinides in Simulated Metallic Waste Forms by Transmission Electron Microscopy
}

prepared by

Engineering Technology Division

Argonne National Laboratory-West 


\section{About Argonne National Laboratory}

Argonne is managed by The University of Chicago for the U.S. Department of Energy under contract W-31-109-Eng-38. The Laboratory's main facility is outside Chicago, at 9700 South Cass Avenue, Argonne, Illinois 60439. For information about Argonne and its pioneering science and technology programs, see www.anl.gov.

\section{Availability of This Report}

This report is available, at no cost, at http://www.osti.gov/bridge. It is also available on paper to U.S. Department of Energy and its contractors, for a processing fee, from:

U.S. Department of Energy

Office of Scientific and Technical Information

P.O. Box 62

Oak Ridge, TN 37831-0062

phone (865) 576-8401

fax (865) 576-5728

reports@adonis.osti.gov

\section{Disclaimer}

This report was prepared as an account of work sponsored by an agency of the United States Government. Neither the United States Government nor any agency thereof, nor The University of Chicago, nor any of their employees or officers, makes any warranty, express or implied, or assumes any legal liability or responsibility for the accuracy, completeness, or usefulness of any information, apparatus, product, or process disclosed, or represents that its use would not infringe privately owned rights. Reference herein to any specific commercial product, process, or service by trade name, trademark, manufacturer, or otherwise, does not necessarily constitute or imply its endorsement, recommendation, or favoring by the United States Government or any agency thereof. The views and opinions of document authors expressed herein do not necessarily state or reflect those of the United States Government or any agency thereof, Argonne National Laboratory, or The University of Chicago. 


\section{Characterization of Host Phases for Actinides in Simulated Metallic Waste Forms by Transmission Electron Microscopy}

by

D.E.Janney*

Engineering Technology Division, Argonne National Laboratory-West

*Current Affiliation: Idaho National Laboratory, P.0.Box 1625, Idaho Falls, ID 83415
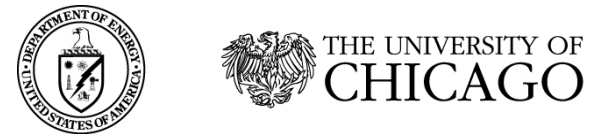


\section{TABLE OF CONTENTS}

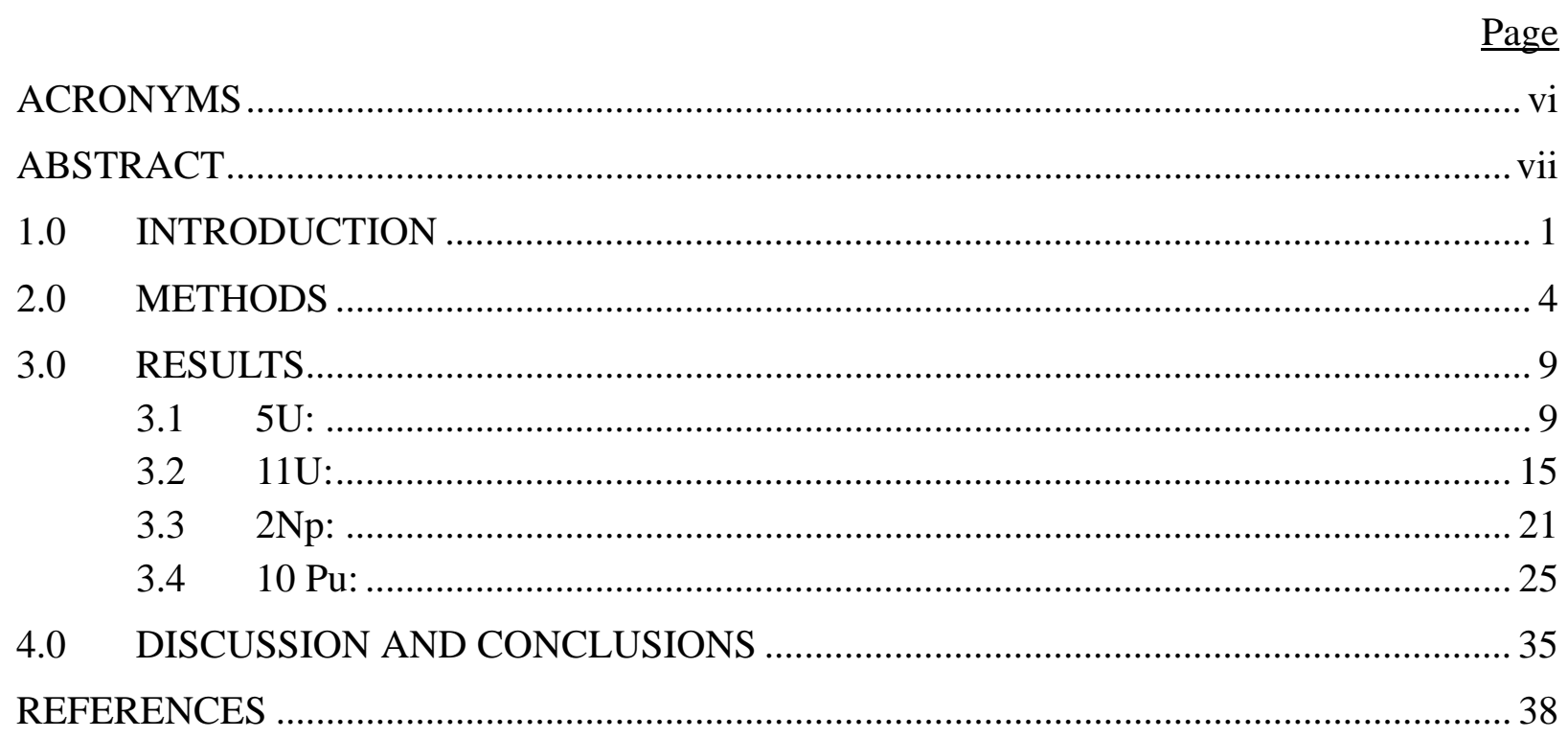




\section{LIST OF FIGURES}

Page

1. Data from Pure SS-15Zr Alloys ................................................................................. 2

2. Previously Reported Compositions of U-rich Laves and Actinide-rich Laves ..................... 3

3. Previously Reported Compositions of Other Laves ....................................................... 4

4. Spontaneously Generated X-rays from $10 \mathrm{Pu}$................................................................ 7

5. Portion of EDX Spectrum 3, 10Pu, Showing Subtraction of Spontaneously

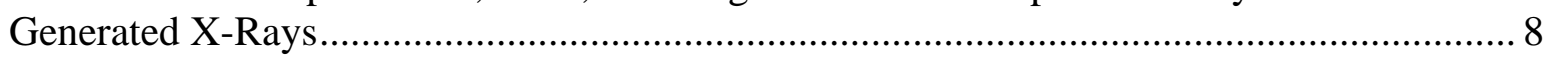

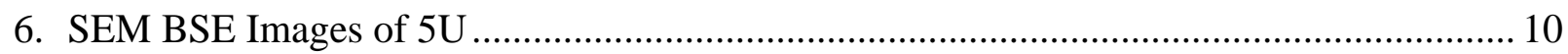

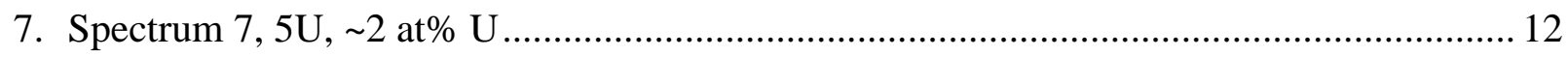

8. Observed Compositional Variations in Regions Having the $\mathrm{Fe}_{23} \mathrm{Zr}_{6}$ Structure ................. 13

9. Observed Compositional Variations in Regions Having the C15 $\mathrm{Fe}_{2} \mathrm{Zr}$ Structure, 5U ........ 13

10. Observed Compositional Variations in Regions Having the C36 Fe $\mathrm{Zr}$ Structure, 5U....... 14

11. F1, F2, and F3 Indicate Examples of Three Orientations of Stacking Faults in 5U............ 15

12. Diffraction Pattern, $\mathrm{C} 36 \mathrm{Fe}_{2} \mathrm{Zr}$ Structure, Shows Rows of Closely Spaced Reflections Whose Spacing Corresponds to $1.6 \mathrm{~nm}$...................................................... 16

13. White Line Follows Transition between $\mathrm{C} 15 \mathrm{Fe}_{2} \mathrm{Zr}$ and $\mathrm{C} 36 \mathrm{Fe}_{2} \mathrm{Zr}$ Structures, Stair-Stepping Along Planar Defects ......................................................................... 16

14. Observed Compositional Variations in Regions Having the C36 Fe 2 Zr Structure, 11U ...... 17

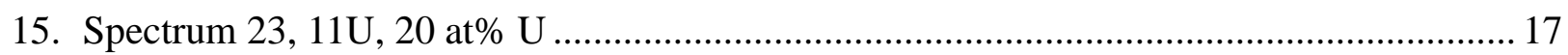

16. Observed Compositional Variations in Regions Having the C15 Fe 2 Zr Structure, 11U ...... 18

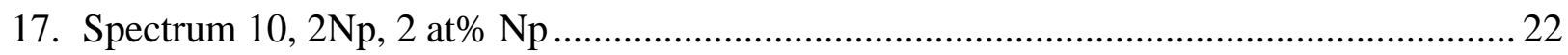

18. Observed Compositional Variation within a Single Crystal of 2Np, Spectra 60-65 ............ 24

19. Compositional Variation in the Entire Sample, $2 \mathrm{~Np}$................................................... 24

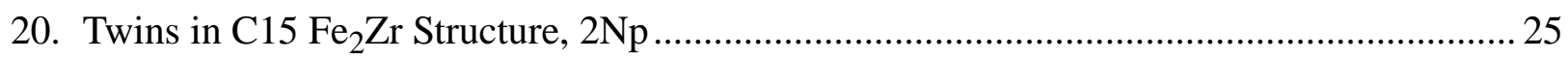

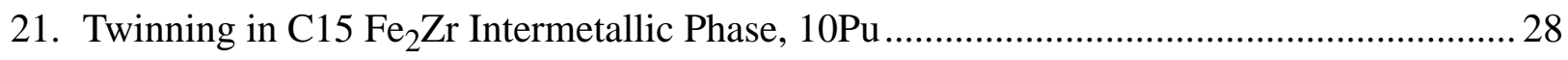

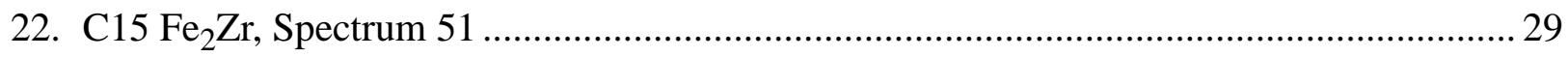

23. Observed Compositional Variations in Regions Having the $\mathrm{C} 15 \mathrm{Fe}_{2} \mathrm{Zr}$ Structure,

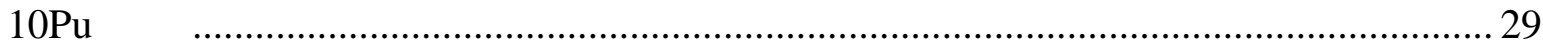

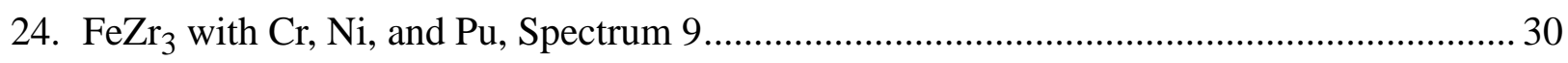

25. Observed Compositions of High-Zr Phases, 10Pu ....................................................... 31

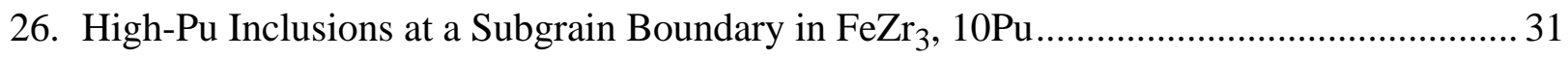

27. High-Pu Inclusion in $\mathrm{FeZr}_{3}$ Spectrum 14 ................................................................ 32

28. High-Pu, High-Mo Phase, Spectrum 57, 10Pu ...........................................................33aa 


\section{LIST OF TABLES}

1. EDX Data from Intermetallic Materials in 5U

$\underline{\text { Page }}$

2. EDX Data from Intermetallic Materials in $11 \mathrm{U}$......................................................... 18

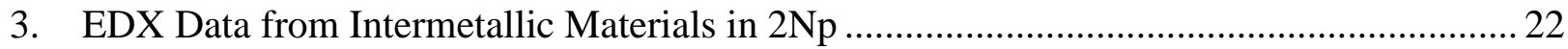

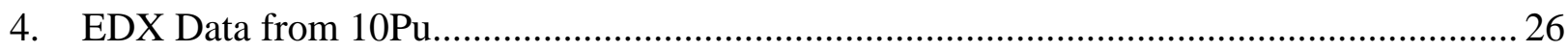

5. EDX Data from the High-Pu, High-Mo Material in 10Pu............................................. 27

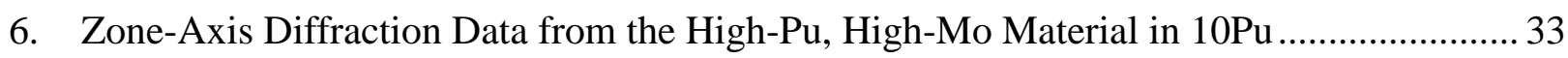


ACRONYMS

BSE Back-Scattered Electron

EDX Energy-Dispersive X-Ray Spectroscopy

SAED Selected-Area Electron Diffraction

SEM Scanning Electron Microscope

TEM Transmission Electron Microscope 


\title{
CHARACTERIZATION OF HOST PHASES FOR ACTINIDES IN SIMULATED METALLIC WASTE FORMS BY TRANSMISSION ELECTRON MICROSCOPY
}

by

D. E. Janney

\begin{abstract}
Argonne National Laboratory has developed an electrometallurgical process for conditioning spent sodium-bonded metallic reactor fuel prior to disposal. A waste stream from this process consists of stainless steel cladding hulls that contain undissolved metal fission products such as Tc, Ru, Rh, Pd, and Ag; a small amount of undissolved actinides (U, Np, Pu) also remains with the hulls. These wastes will be immobilized in a waste form whose baseline composition is stainless steel alloyed with $15 \mathrm{wt} \% \mathrm{Zr}$ (SS-15Zr). Scanning electron microscope (SEM) observations of simulated metal waste forms (SS-15Zr with added actinides) show eutectic intergrowths of iron solid-solution ("steel") and Fe-Zr-Cr-Ni ("intermetallic") materials. The actinide elements are almost entirely in the intermetallic materials, where they occur in concentrations as high as 20 at\%. Neutron- and electron-diffraction studies of the simulated waste forms show materials with structures similar to those of $\mathrm{Fe}_{2} \mathrm{Zr}$ and $\mathrm{Fe}_{23} \mathrm{Zr}_{6}$.
\end{abstract}

New TEM observations of simulated waste form samples with compositions SS-15Zr-2Np, SS-15Zr-5U, SS-15Zr-11U-0.6Ru-0.3Tc-0.1Pd, and SS-15Zr-10Pu suggest that the major U- and Pu-bearing phase has a structure similar to that of the C15 (cubic, $\mathrm{MgCu}_{2}$-type) polymorph of $\mathrm{Fe}_{2} \mathrm{Zr}$. Materials with this structure exhibit significant variability in chemical compositions and actinide concentrations up to 20 at\% (normalized so that atomic fractions of $\mathrm{Cr}, \mathrm{Ni}, \mathrm{Fe}$, and $\mathrm{Zr}$ add up to 1). A U-bearing material similar to the C36 (dihexagonal, $\mathrm{MgNi}_{2}$-type) polymorph of $\mathrm{Fe}_{2} \mathrm{Zr}$ was also observed. Chemical variability in materials with the $\mathrm{C} 36 \mathrm{Fe}_{2} \mathrm{Zr}$ structure is smaller than in those with the $\mathrm{C} 15 \mathrm{Fe}_{2} \mathrm{Zr}$ structure, and $\mathrm{U}$ concentrations are less than 5 at\%. Uranium concentrations up to 5 at.\% were observed in materials with the $\mathrm{Fe}_{23} \mathrm{Zr}_{6}$ (cubic, $\mathrm{Mn}_{23} \mathrm{Th}_{6}$-type) structure.

Microstructures similar to those produced during experimental deformation of $\mathrm{Fe}-10$ at\% $\mathrm{Zr}$ alloys were observed in intermetallic materials in all of the simulated waste form samples. Stacking faults and associated dislocations are common in samples with $\mathrm{U}$, but rarely observed in those with $\mathrm{Np}$ and $\mathrm{Pu}$, while twins occur in all samples. Previously reported differences in dissolution behavior between samples with different actinides may be related to increased defectassisted dissolution in samples with $\mathrm{U}$. 


\subsection{INTRODUCTION}

This report summarizes research involving characterization of host phases for actinides in simulated metallic waste form ingots with nominal compositions SS-15Zr-5U, SS-15Zr-11U0.6Ru-0.3Tc-0.1Pd, SS-15Zr-2Np, and SS-15Zr-10Pu, where numbers indicate weight percents of constituent elements and "SS" indicates that the remaining material is type 316 stainless steel. In the rest of this paper, the samples will be referred to as " $5 \mathrm{U}$," "11U," "2Np," and " $10 \mathrm{Pu}$ " respectively.

Experimental measurements of elemental releases during immersion tests of actinide-bearing simulated metallic waste forms consistently show that the normalized release rate of $\mathrm{U}$ is higher than that of any other constituent, including Fe [1-3]. Previous attempts to understand this behavior have included characterization of actinide-bearing phases using scanning electron microscope (SEM) and neutron-diffraction data [4]. The SEM data provide information about the chemistry of actinide-bearing phases but do not allow direct identification of crystal structures. Neutron-diffraction data provide information about crystal structures but not chemical compositions. The present study correlates structural, microstructural, and chemical characteristics to provide information about the host phases for actinide elements in simulated metallic waste forms. This information is necessary to understand the anomalous $\mathrm{U}$ release rates.

Scanning electron microscope observations of alloys containing $85 \mathrm{wt} \%$ type 316 stainless steel and $15 \mathrm{wt} \% \mathrm{Zr}$ (SS-15Zr) (e.g., [5]) show that the alloys form eutectic microstructures between iron solid-solution and Fe-Cr-Ni-Zr phases. For convenience, the iron solid-solution phases are referred to in this report as "steels," or as "ferrite" or "austenite" to indicate structural information. The Fe-Cr-Ni-Zr phases are commonly referred to as "Laves" or "intermetallic" phases because of their structural similarities to pure Fe-Zr phases.

Neutron diffraction studies of SS-15Zr $[5,6]$ indicate the presence of materials with structures similar to those of the $\mathrm{C} 15$ (cubic, $\mathrm{MgCu}_{2}$-type) and C36 (dihexagonal, $\mathrm{MgNi}_{2}$-type) polytypes of $\mathrm{Fe}_{2} \mathrm{Zr}$ and a material with the $\mathrm{Fe}_{23} \mathrm{Zr}_{6}$ (cubic, $\mathrm{Mn}_{23} \mathrm{Th}_{6}$-type) structure. A material whose crystal structure is similar to that of the $\mathrm{C} 14$ (hexagonal, $\mathrm{MgZn}_{2}$-type) polytype of $\mathrm{Fe}_{2} \mathrm{Zr}$ occurs in SS-42Zr alloys and may be present in small quantities in SS-15Zr [5, 6].

Chemical compositions measured using an SEM with EDX in intermetallic areas of SS-15Zr have been interpreted as representing materials with the $\mathrm{C} 15 \mathrm{Fe}_{2} \mathrm{Zr}$, C36 Fe $2 \mathrm{Zr}$, and $\mathrm{Fe}_{23} \mathrm{Zr}_{6}$ structures (Fig. 1) [7]. The $\mathrm{Fe}_{2} \mathrm{Zr}$-type materials contain 24 at\% $\mathrm{Zr}$ (significantly less than the $33 \%$ required for stoichiometry). The $\mathrm{Fe}_{23} \mathrm{Zr}_{6}$-type material contains 20.5 at $\% \mathrm{Zr}$ (as compared to $20.7 \%$ for stoichiometry). The primary chemical difference between the $\mathrm{Fe}_{2} \mathrm{Zr}$-type materials is the $\mathrm{Ni} / \mathrm{Cr}$ ratio, which is $>2.5$ for C15-type materials and $\sim 1.5$ for C36-type [7]. The $\mathrm{Fe}_{23} \mathrm{Zr}_{6^{-}}$ type material has a $\mathrm{Ni} / \mathrm{Cr}$ ratio of $\sim 1$ [7]. The $\mathrm{Fe}_{2} \mathrm{Zr}$-type phases cannot be distinguished from each other in SEM images; the $\mathrm{Fe}_{23} \mathrm{Zr}_{6}$-type material has a distinctive polygonal crystal habit [5, 6]. 


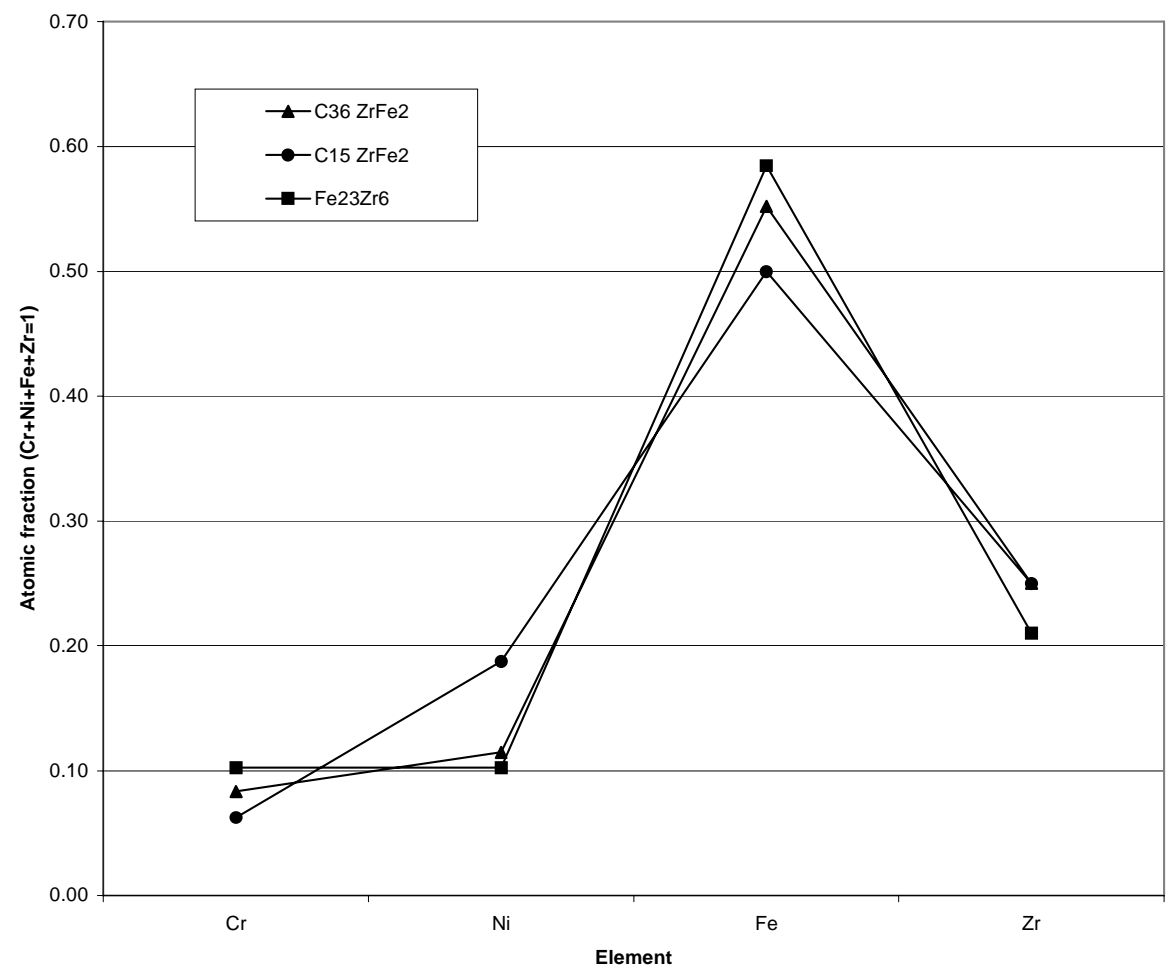

Fig. 1. Data from Pure SS-15Zr Alloys [7]

Scanning electron microscope images of actinide- and Tc-bearing alloys based on SS-15Zr [4, 8] show eutectic microstructures similar to those in pure SS-15Zr. Neutron-diffraction data show the presence of materials with the $\mathrm{C} 15 \mathrm{Fe}_{2} \mathrm{Zr}$, C36 Fe $2 \mathrm{Zr}$, and $\mathrm{Fe}_{23} \mathrm{Zr}_{6}$ structures. A structure similar to a six-layer hexagonal $(6 \mathrm{H})$ polytype of $\mathrm{Fe}_{2} \mathrm{Zr}[9,10]$ was observed in SS-15Zr-5U-2Tc [4]. The SEM data show that the actinide elements are located almost entirely in the intermetallic phases [4] (Fig. 2 and Fig. 3). Actinide concentrations are highest in the brightest areas in backscattered electron (BSE) images of the intermetallic phases, and lowest in the darkest areas. Although actinide concentrations can vary markedly within a small area, there are no clear boundaries between adjacent high- and low-actinide areas. Previous transmission electron microscope (TEM) work on a sample of SS-15Zr-5U-2Tc suggests that the actinide concentration gradients may result from a sequence of polytypes, each with a different actinide concentration [4]. 


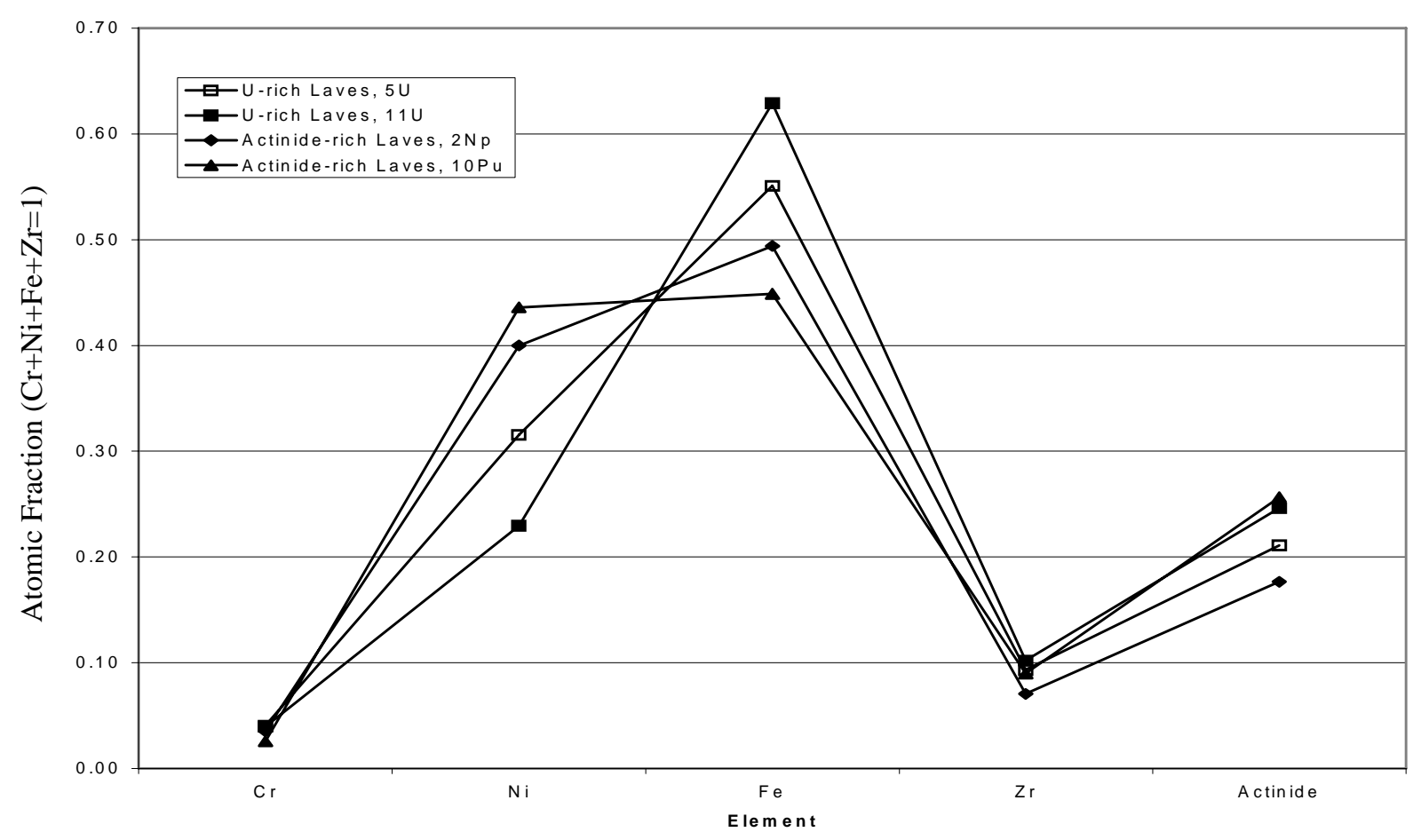

Fig. 2. U-rich Laves (in 5U and 11U) and Actinide-rich Laves (in 2NP and10Pu) [4]

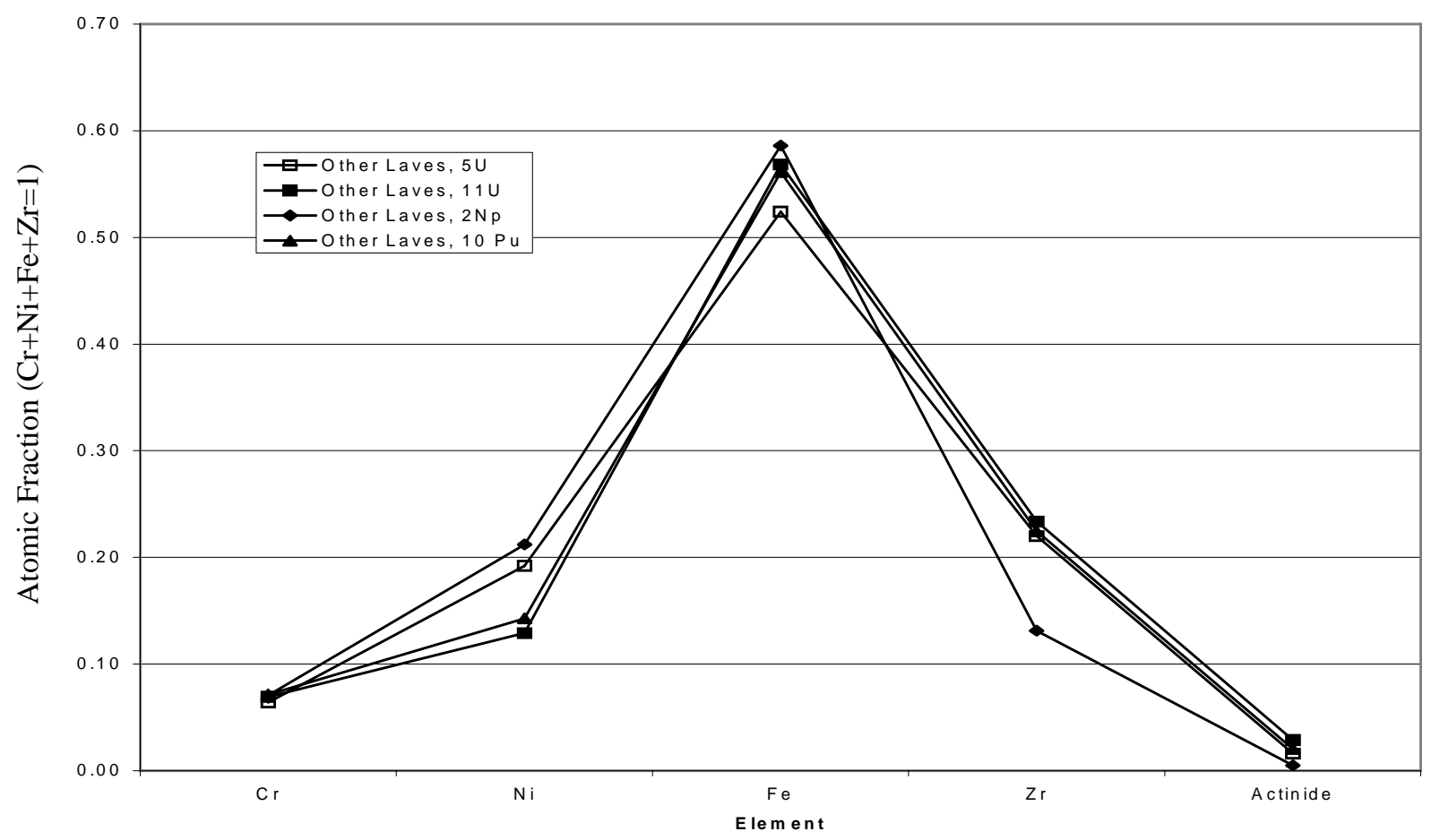

Fig. 3. Other Laves (All Samples) [5] 
The stability of the $\mathrm{Fe}_{2} \mathrm{Zr}$ polytypes has been related to the ratios of the atomic diameters of the phases [4, 9, 11], to electron concentration [4, 11], and to thermodynamic considerations [4]. These criteria have not been rigorously applied to the materials discussed in this report. Thus, our knowledge of relationships between crystal structures and compositions rests on accumulated empirical observations of the kind presented here rather than direct application of physical and chemical principles.

\subsection{METHODS}

Ingots were prepared by melting metal charges in yttrium oxide crucibles, holding them at $1600^{\circ} \mathrm{C}$ under flowing argon for $1-2$ hours, and cooling them to room temperature slowly $\left(<10^{\circ} \mathrm{C} / \mathrm{min}\right)$. The $2 \mathrm{~Np}, 5 \mathrm{U}$, and $10 \mathrm{Pu}$ ingots were prepared in an induction furnace. The $11 \mathrm{U}$ ingot was prepared in a resistance furnace [4].

Transmission electron microscope samples of $2 \mathrm{~Np}$ and $5 \mathrm{U}$ were prepared by cutting slices from the ingots with a low-speed saw, grinding the slices to a thickness of $<100$ microns and breaking them into small pieces. The pieces were individually ground to a maximum thickness of approximately 30 microns, ending with a 1200-grit finish on each side. Each piece was glued to a single-hole copper TEM grid and ion milled to perforation. Samples of $10 \mathrm{Pu}$ and $11 \mathrm{U}$ were prepared by cutting slices from the ingots, grinding to a thickness of 200-300 microns, and producing 3mm diameter disks with a disc punch. Each disk was ground to a thickness of $\sim 50-90$ microns, ending with a 1200-grit finish on one side. The side without the 1200-grit finish was dimpled with 0-2 micron cubic boron nitride abrasive to an estimated thickness of 20-30 microns at the bottom of the dimple, and the disk was then ion milled to perforation.

Transmission electron microscope observations were carried out using a JEOL 2010 TEM operating at $200 \mathrm{kV}$ and equipped with a double-tilt $\left( \pm 20^{\circ}, \pm 30^{\circ}\right)$ analytical sample holder and an Oxford Link EDX detector with a SiLi crystal and ISIS Suite Revision 3.2 software. Both diffraction and EDX data were collected from a number of areas in each sample, allowing precise correlation of crystallographic and chemical characteristics in these areas. EDX spectra were also collected from areas without diffraction data to document chemical variability within single crystals and entire samples.

Crystal structures were identified by comparing d-spacings and interplanar angles from experimental selected-area electron diffraction (SAED) patterns to those produced by candidate structure models from phases with similar compositions. The structure models used were ferrite [5], austenite [5], C14 Fe $2 \mathrm{Zr}$ [5, 12], C15 Fe $\mathrm{Zr}$ [5, 12], C36 Fe $\mathrm{Zr}$ [5, 12], $\mathrm{Fe}_{23} \mathrm{Zr}_{6}$ [5, 12], tetragonal [12, 13] and cubic [12] polymorphs of $\mathrm{FeZr}_{2}, \mathrm{FeZr}_{3}$ [12], hexagonal and orthorhombic polymorphs of $\mathrm{FeZr}_{4}[12,14], \alpha-\mathrm{Zr}$ [15], $\beta-\mathrm{Zr}$ [15], and $\omega-\mathrm{Zr}$ [15]. Information about the sixlayer structure in SS-15Zr-5U-2Tc [4] was not complete enough to allow calculations of interplanar spacings and angles; however, diffraction patterns from this phase would be readily recognizable because of the closely spaced reflections produced by the large stacking periodicity.

The $\mathrm{C} 36 \mathrm{Fe}_{2} \mathrm{Zr}$ and $\mathrm{Fe}_{23} \mathrm{Zr}_{6}$ structures produce distinctive diffraction patterns with closely spaced reflections when viewed from some crystallographic orientations, and thus in many cases can be identified from a single diffraction pattern. When viewed from other orientations, both 
structures can also produce diffraction patterns indistinguishable from those representing major zone axes in the $\mathrm{C} 15 \mathrm{Fe}_{2} \mathrm{Zr}$ structure.

Structures producing these diffraction patterns were identified by tilting the sample through the full range allowed by the specimen holder and recording all major zone-axis patterns. Stereographic projections and simulated diffraction patterns demonstrate that the entire reciprocal space of both the $\mathrm{C} 36 \mathrm{Fe}_{2} \mathrm{Zr}$ and $\mathrm{Fe}_{23} \mathrm{Zr}_{6}$ structures is within 20 degrees of a zone axis producing a distinctive diffraction pattern. As a consequence, at least one distinctive pattern can be observed when any sample with either of these structures is tilted through the full range allowed by the specimen holder. Similar criteria can be used to eliminate the $\mathrm{C}_{14} \mathrm{Fe}_{2} \mathrm{Zr}$ structure. Thus, the absence of distinctive patterns from other structures in tilting experiments is diagnostic of the $\mathrm{C} 15 \mathrm{Fe}_{2} \mathrm{Zr}$ structure, assuming that it can produce all of the individual experimental diffraction patterns.

Collection times for EDX data ranged from 50 to 1200 live seconds, depending on the importance assigned to finding and identifying small peaks. The Link Isis software was used to quantify major elements (Fe, Cr, Ni, and $\mathrm{Zr}$ ) in 5U, 11U, and 2Np, $\mathrm{U}$ in and $5 \mathrm{U}$ and $11 \mathrm{U}$, and Fe, $\mathrm{Cr}$, and $\mathrm{Ni}$ in $10 \mathrm{Pu}$. Quantification of $\mathrm{Np}$ in $2 \mathrm{~Np}$, and of $\mathrm{Pu}$ and $\mathrm{Zr}$ in $10 \mathrm{Pu}$, required a different approach based on fundamental principles of spectrum generation and data reduction for EDX data collected in a TEM.

Quantification of intensities from EDX spectra collected in a TEM commonly uses proportionality constants called "k-factors" or "Cliff-Lorimer factors" relating the relative intensities of X-rays from two elements to their relative masses [16]. When relative masses of all elements of interest have been determined, they can be converted to absolute concentrations by appropriate normalization. Thus, the approximate concentration of $\mathrm{Np}$ relative to that of $\mathrm{Fe}\left(C_{\mathrm{Np}} / C_{\mathrm{Fe}}\right)$ was calculated using the ratio of the intensities of $\mathrm{Np} \mathrm{L}_{\alpha}$ and $\mathrm{Fe} \mathrm{K}_{\alpha}$ $\mathrm{X}$-rays $\left(I_{\mathrm{Np}} / I_{\mathrm{Fe}}\right)$ and the k-factor $\left(k_{N p / F e}\right)$ relating the two:

$$
\frac{C_{N p}}{C_{F e}}=k_{N p, F e} \frac{I_{N p}}{I_{F e}}
$$

Calculation of the approximate concentration of $\mathrm{Pu}$ relative to that of $\mathrm{Fe}$ using the relative intensities of X-rays from both elements was similar.

$\mathrm{X}$-ray intensities for $\mathrm{Np}$ were calculated for each spectrum from intermetallic materials in $2 \mathrm{~Np}$ by interpolating a linear background across an energy window including the $\mathrm{Np} \mathrm{L}_{\alpha}$ peak and calculating the above-background intensity under the peak. A similar approach was used to calculate the intensities of the $\mathrm{Zr} \mathrm{K} \mathrm{K}_{\alpha}$ peaks for comparison to those calculated by the Link Isis software.

Determination of x-ray intensities for Pu was more complicated. EDX spectra from 10Pu are combinations of characteristic X-rays generated by interactions between the electron beam and the sample and X-rays produced spontaneously by other processes when the electron beam is turned off (Fig. 4). Comparison of spectra collected from the same area of the specimen with the 
beam on and off suggests that the beam does not affect the intensities of the spontaneously generated X-rays. Thus, higher count rates were used for spectra collected towards the end of the study to increase the relative contribution of X-rays generated by sample-beam interactions. Count rates were increased by adjusting lens settings to produce a more intense electron beam at the sample and by collecting data from thicker areas. Six spectra were collected with the beam off. Relative peak heights in these spectra appear consistent, although absolute peak heights differ by a factor of 2-3 even between spectra collected with the same counting time. There is no obvious relationship between the intensities of the spontaneously generated $\mathrm{X}$-rays and the sample composition in the area of the electron beam.

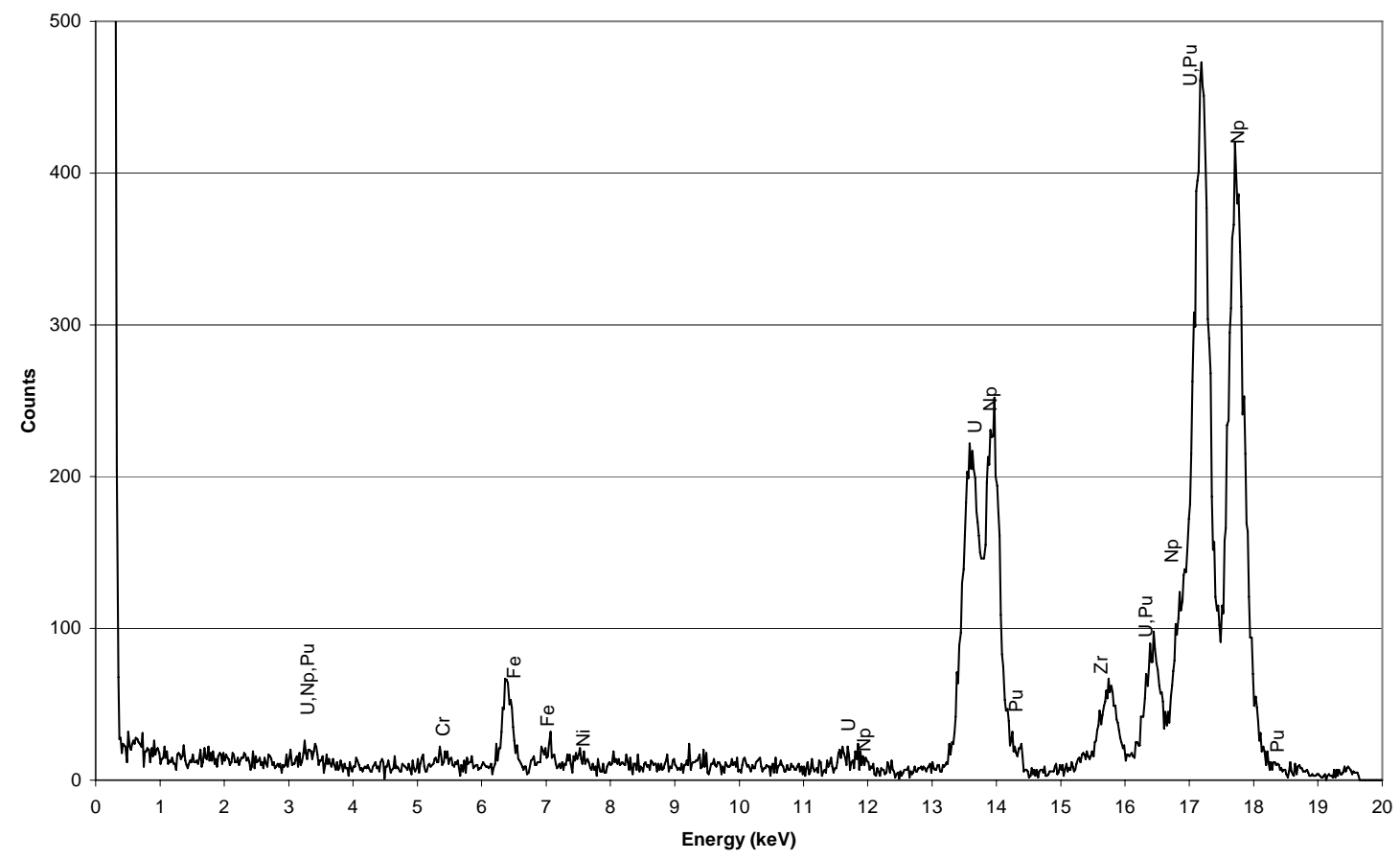

Fig. 4. Spontaneously Generated X-rays from $10 \mathrm{Pu}$

Intensities of the $\mathrm{Zr} \mathrm{K} \mathrm{K}_{\alpha}$ and $\mathrm{Pu} \mathrm{L} \mathrm{L}_{\alpha}$ X-rays were determined in two steps for each EDX data spectrum from $10 \mathrm{Pu}$ :

- $\quad$ Subtraction of an appropriate spectrum collected with the beam off, (eg., Fig. 4) and

- $\quad$ Calculation of intensities in the remaining spectrum above a linear background (Fig. 5, in which the original spectrum is shown in gray, the spectrum after subtraction of the spontaneously generated x-rays is shown in black, and the linear background is shown by a straight heavy line).

Three criteria were used to determine which spontaneously generated spectrum should be subtracted: 
- $\quad$ The subtracted spectrum and data spectrum should have the same counting time;

- $\quad$ They should be from the same general area of the specimen; and

- $\quad$ The result of the subtraction should be approximately linear across the energy range corresponding to the $\mathrm{U} \mathrm{L}_{\alpha}$ peak (which is conspicuous in all spectra collected with the beam off but should be negligible in a sample whose nominal composition does not include $\mathrm{U}$ ).

When more than one of the criteria were applicable, each led to choosing the same spectrum for subtraction. After the subtraction, calculation of intensities above a linear background was similar to that for 2Np spectra.

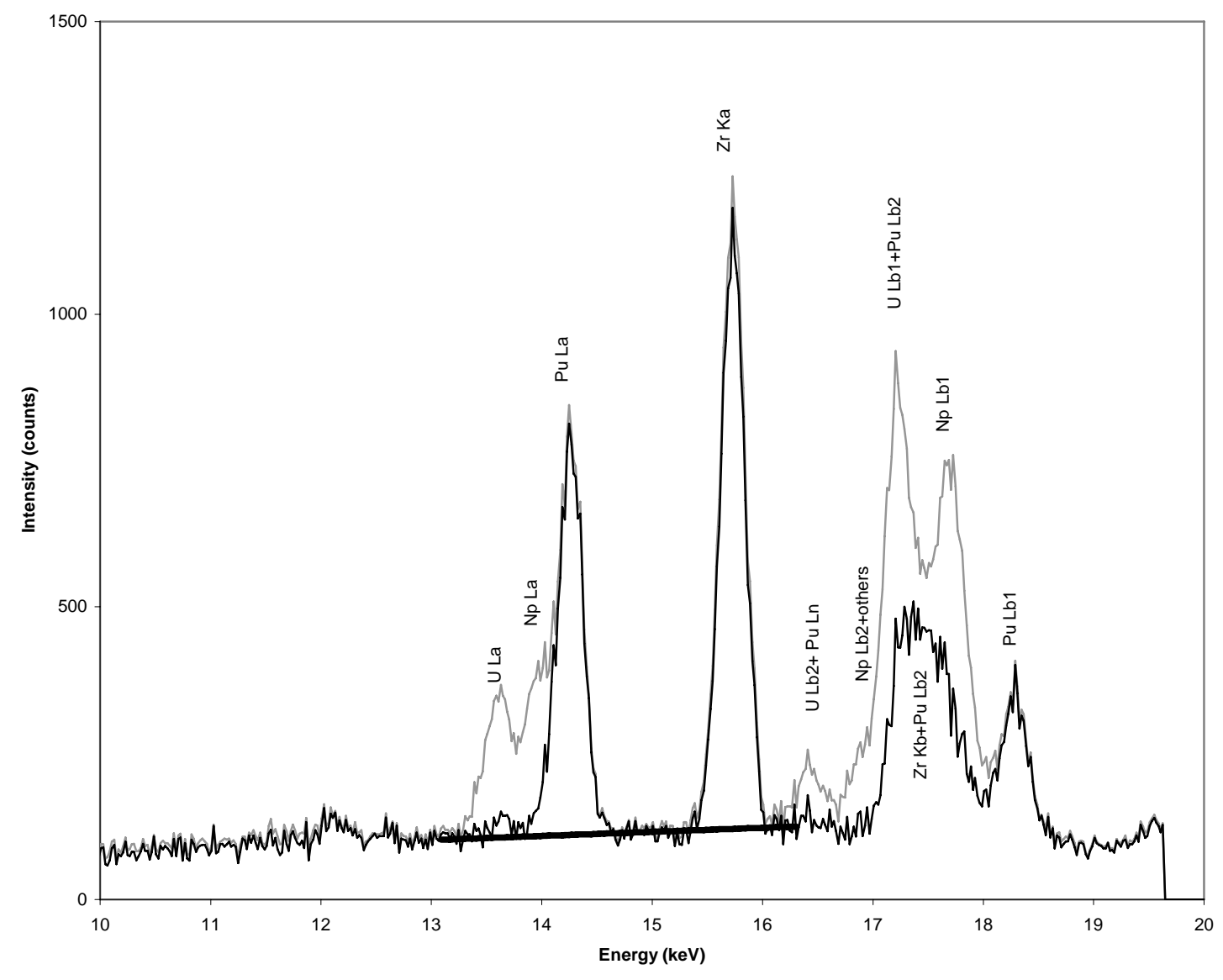

Fig. 5. Portion of EDX Spectrum 3, $10 \mathrm{Pu}$, Showing Subtraction of Spontaneously Generated X-Rays

K-factors relating relative intensities of $\mathrm{Np}$ and $\mathrm{Pu} \mathrm{X}$-rays to those of any other element were not available. However, the Link Isis software supplies k-factors relating $\mathrm{L}_{\alpha} \mathrm{X}$-rays for atomic numbers 58-83 (Ce through $\mathrm{Bi}$ ) to $\mathrm{Fe} \mathrm{K}_{\alpha} \mathrm{X}$-rays. A cubic polynomial relating these $\mathrm{k}$-factors to atomic numbers produced an excellent fit (R-value $>0.999$ ). K-factors for $\mathrm{Np}_{\alpha}$ and $\mathrm{Pu} \mathrm{L}_{\alpha}$ 
relative to $\mathrm{Fe} \mathrm{K}_{\alpha}$ were approximated by extrapolating this polynomial to $\mathrm{Np}$ and $\mathrm{Pu}$ (atomic numbers 93 and 94). Although this procedure is admittedly somewhat ad hoc, it does allow semiquantitative concentrations of $\mathrm{Np}$ and Pu to be determined.

Figures 5a, 5b, and 5c show spectra with different concentrations of actinides. Note that the sizes of the Np peaks in Fig. 5a are similar to those of the U peaks in Fig. 5b, but are much smaller than the U peaks in Fig. 5c. Concentrations of Np and U in Fig. 5a and Fig. 5b are both 2\%, that of $\mathrm{U}$ in Fig. $5 \mathrm{c}$ is $\sim 20 \%$.

Intensities for $\mathrm{Zr} \mathrm{K} \mathrm{K}_{\alpha}$ peaks calculated by subtraction of a linear background from EDX spectra from $2 \mathrm{~Np}$ are commonly larger than those from Link Isis by at least $10 \%$. However, a comparison of elemental compositions calculated using intensities from both sources shows that the atomic fractions of Zr calculated from the two intensities agree to within a few percent. This difference is comparable to that between $\mathrm{Zr}$ contents calculated by the Link Isis software using the $\mathrm{Zr} \mathrm{K} \mathrm{K}_{\alpha}$ and $\mathrm{Zr} \mathrm{L} \mathrm{L}_{\alpha}$ peaks.

In EDX data from $10 \mathrm{Pu}$, concentrations of $\mathrm{Zr}$ calculated by the Link Isis software from $\mathrm{Zr} \mathrm{K}_{\alpha}$ and $\mathrm{Zr} \mathrm{L}_{\alpha}$ X-rays in the same spectrum commonly differ by $10-20 \%$; differences of $30 \%$ occurred in a few spectra. These differences probably reflect errors in both concentrations: intensities from $\mathrm{Zr} \mathrm{L}{ }_{\alpha} \mathrm{X}$-rays are anomalously low because of absorption in thicker areas of the specimen, while intensities from $\mathrm{Zr} \mathrm{K}_{\alpha}$ X-rays are anomalously high because they include the spontaneously generated X-rays. Zirconium concentrations calculated from the intensity of the $\mathrm{Zr} \mathrm{K} \alpha$ peak after subtraction of a spontaneously generated spectrum and a linear background are used in this report. These concentrations fall between the values calculated by the Link Isis software from the $\mathrm{Zr} \mathrm{K} \mathrm{K}_{\alpha}$ and $\mathrm{Zr} \mathrm{L} \mathrm{L}_{\alpha}$ peaks except for spectra with the highest total counts, where all three calculated Zr concentrations are similar.

In the rest of this report, information about $\mathrm{Pu}$ concentrations in 10Pu is expressed as the ratio of the intensities of the $\mathrm{Pu} \mathrm{L} \mathrm{L}_{\alpha}$ and $\mathrm{Zr} \mathrm{K} \mathrm{K}_{\alpha}$ peaks and as an elemental fraction of Pu. The total counts from major elements in each spectrum is also listed, as any errors from imperfect elimination of the spontaneously generated part of the spectrum become less significant in spectra with more counts. Information about the Np concentration is expressed both as the ratio of the intensities of the $\mathrm{Np} \mathrm{L}_{\alpha}$ and $\mathrm{Zr} \mathrm{K}_{\alpha}$ peaks and as an elemental fraction of $\mathrm{Np}$. 


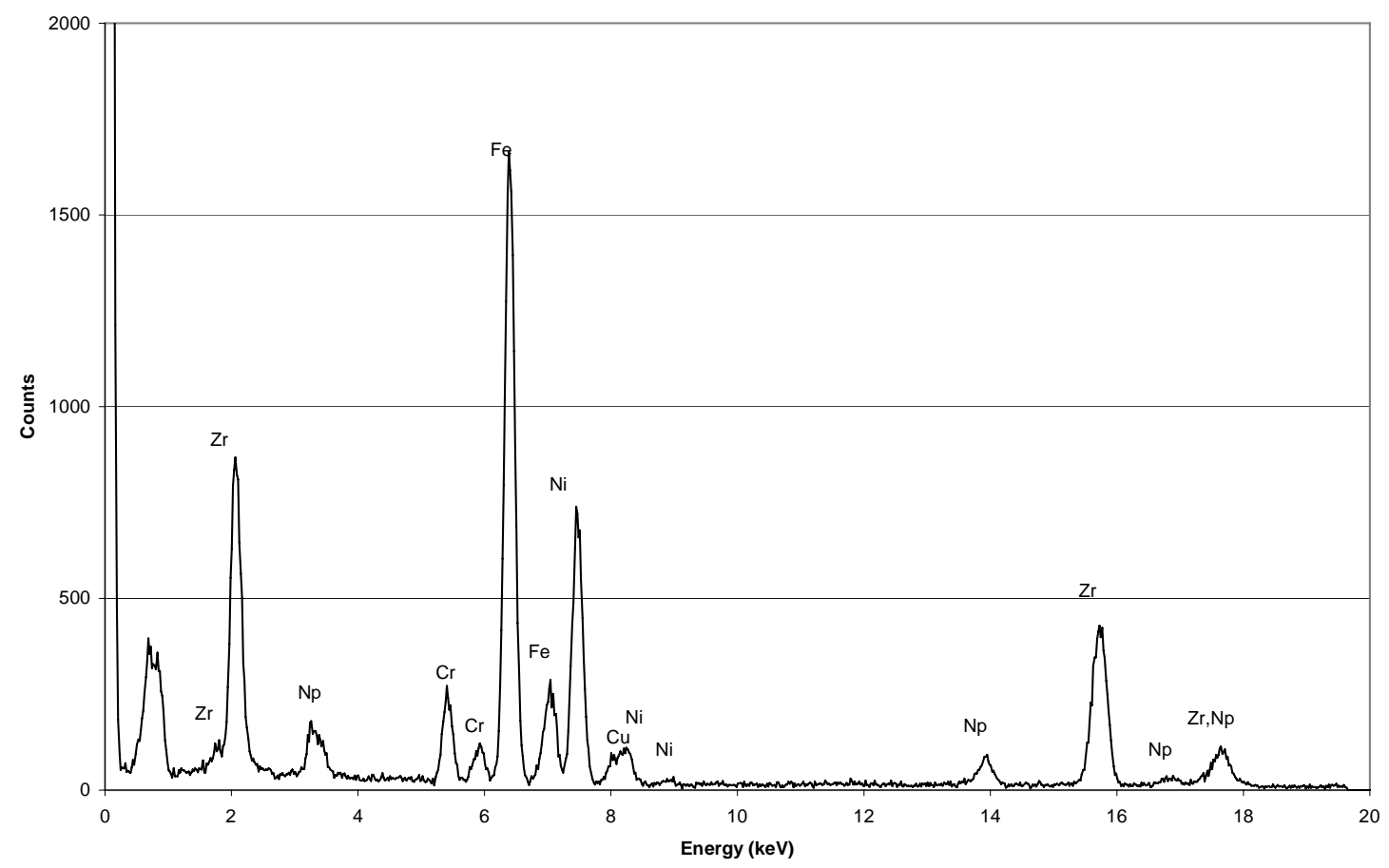

Fig. 5a. Spectrum 10, 2Np, 2 at\% Np

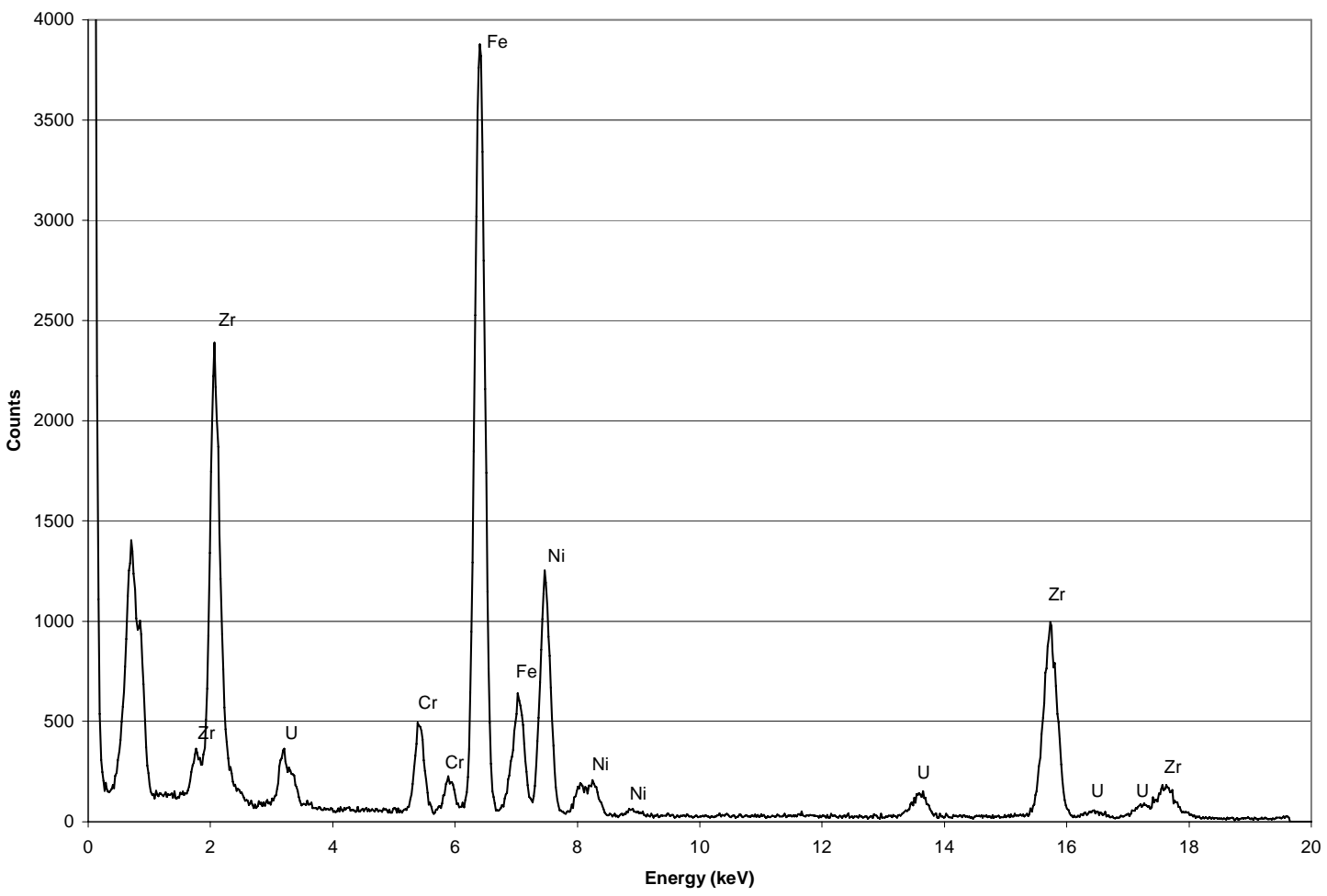

Fig. 5b. Spectrum 7, 5U, 2 at\% U 


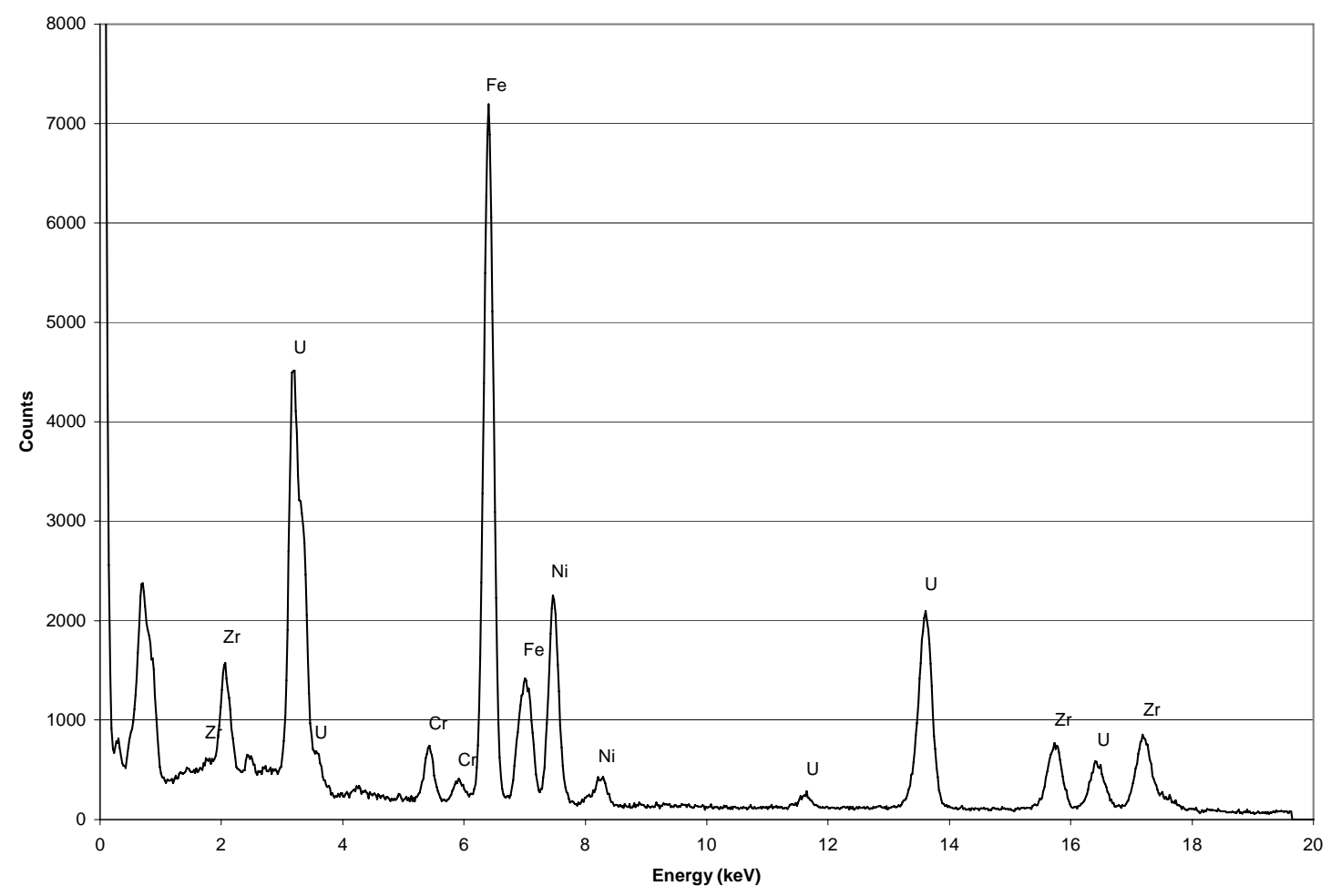

Fig. 5c. Spectrum 23, 11U, 20 at\% U

\subsection{RESULTS}

The data in this section are based on TEM examination of seven specimens: two of 5U, two of $11 \mathrm{U}$, one of $2 \mathrm{~Np}$, and two of $10 \mathrm{Pu}$. Several of the samples were examined more than once, with additional ion milling to expose new areas of the specimen between examinations. Most of the samples had several ion-milled holes tens or hundreds of microns apart.

\section{$3.15 \mathrm{U}:$}

Scanning electron microscope data were collected from a slice of $5 \mathrm{U}$ before small amounts were extracted for preparation as TEM samples. They show that most of the sample has a eutectic microstructure typical of that reported from other SS-15Zr samples (e.g., [17]). However, there are several areas of low-U polygonal crystals at edges of Zr-lined cracks (Fig. 6). X-ray mapping shows small regions with high Zr within the polygonal crystals. Small ( $<1$ micron across), highactinide areas separate some of the polygonal crystals. The morphology of the polygonal crystals [18-20] and their association with $\mathrm{Zr}$ [20] are both characteristic of $\mathrm{Fe}_{23} \mathrm{Zr}_{6}$. 


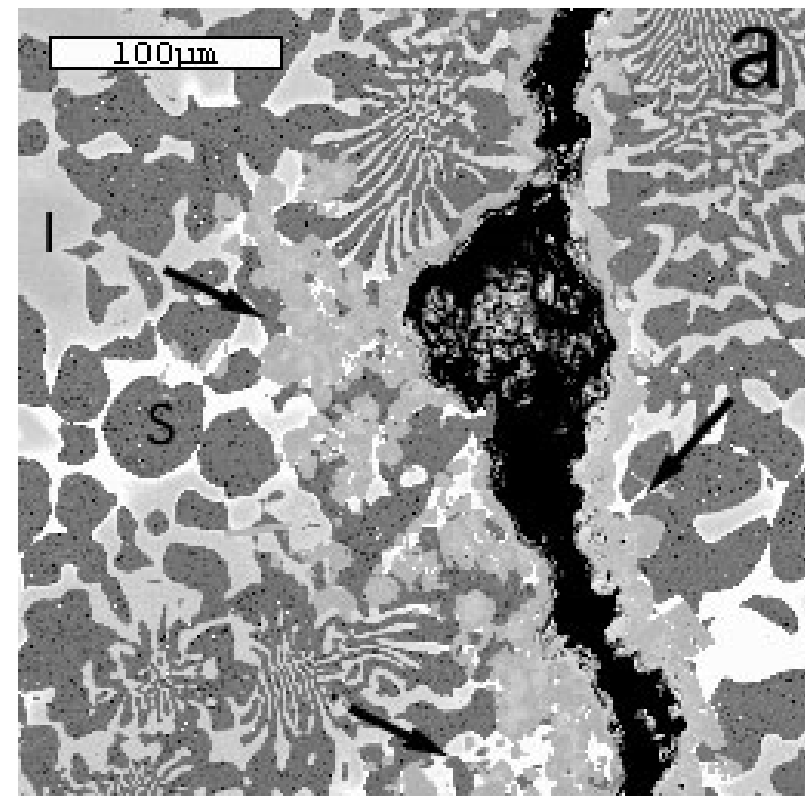

(a) Zr-lined Crack with Associated Areas of Polygonal Crystals, Probably $\mathrm{Fe}_{23} \mathrm{Zr}_{6}$

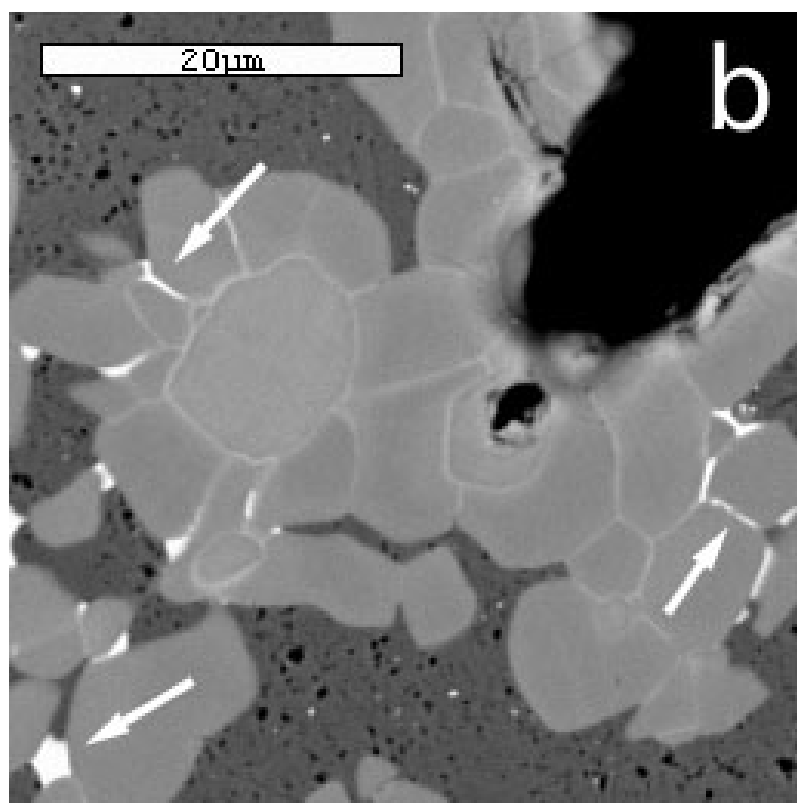

(b) Small White Areas Indicate High-Actinide Regions between Polygonal Crystals at the Edge of a Crack or Hole in the Specimen

Fig. 6. SEM BSE Images of $5 U$ (medium gray areas indicated by "S" are steel, lighter areas indicated by "I" are intermetallics)

Transmission electron microscope data from intermetallic phases in 5U include over 75 zoneaxis diffraction patterns and 45 EDX spectra. Most of the data are from areas with the $\mathrm{C}_{36} \mathrm{Fe}_{2} \mathrm{Zr}$ structure. However, several crystals with the $\mathrm{Fe}_{23} \mathrm{Zr}_{6}$ structure were found in a specimen prepared from an area where SEM data indicated that this phase was common, and some material with the $\mathrm{C} 15 \mathrm{Fe}_{2} \mathrm{Zr}$ structure was also identified. Some crystals with $\mathrm{Fe}_{23} \mathrm{Zr}_{6}$ structures (e.g., spectrum 47, Table 1) have $~ 5 \%$ U. Energy-dispersive X-ray data from intermetallics in $5 \mathrm{U}$ (Fig. 5b, Fig. 7, Fig. 8, Fig. 9, and Table 1) show slight differences in major-element concentrations from the different crystal structures. However, the compositional variation within each structure is at least as large as that between structures.

Table 1. EDX Data from Intermetallic Materials in 5U

\begin{tabular}{|c|c|c|c|c|c|}
\hline Spectrum & $\mathrm{Cr}$ & $\mathrm{Ni}$ & $\mathrm{Fe}$ & $\mathrm{Zr}$ & $\mathrm{U}$ \\
\hline \hline 2 & 0.07 & 0.12 & 0.53 & 0.27 & 0.01 \\
\hline 3 & 0.08 & 0.13 & 0.53 & 0.27 & 0.01 \\
\hline 4 & 0.05 & 0.19 & 0.51 & 0.26 & 0.01 \\
\hline 7 & 0.06 & 0.16 & 0.52 & 0.26 & 0.02 \\
\hline 8 & 0.08 & 0.11 & 0.53 & 0.27 & 0.00 \\
\hline
\end{tabular}


Table 1. (Contd.)

\begin{tabular}{|c|c|c|c|c|c|}
\hline Spectrum & $\mathrm{Cr}$ & $\mathrm{Ni}$ & $\mathrm{Fe}$ & $\mathrm{Zr}$ & $\mathrm{U}$ \\
\hline 10 & 0.08 & 0.12 & 0.52 & 0.29 & 0.00 \\
\hline 11 & 0.08 & 0.10 & 0.52 & 0.29 & 0.00 \\
\hline 12 & 0.09 & 0.11 & 0.52 & 0.28 & 0.00 \\
\hline 14 & 0.07 & 0.12 & 0.53 & 0.28 & 0.01 \\
\hline 15 & 0.07 & 0.14 & 0.52 & 0.28 & 0.01 \\
\hline 16 & 0.06 & 0.14 & 0.52 & 0.28 & 0.01 \\
\hline 18 & 0.07 & 0.12 & 0.53 & 0.28 & 0.01 \\
\hline 19 & 0.08 & 0.12 & 0.54 & 0.26 & 0.00 \\
\hline 20 & 0.07 & 0.14 & 0.52 & 0.27 & 0.01 \\
\hline 21 & 0.07 & 0.14 & 0.53 & 0.27 & 0.01 \\
\hline 22 & 0.08 & 0.10 & 0.53 & 0.29 & 0.00 \\
\hline 23 & 0.09 & 0.11 & 0.52 & 0.28 & 0.00 \\
\hline 24 & 0.09 & 0.11 & 0.52 & 0.28 & 0.00 \\
\hline 25 & 0.08 & 0.11 & 0.53 & 0.28 & 0.00 \\
\hline 26 & 0.09 & 0.10 & 0.53 & 0.28 & 0.00 \\
\hline 27 & 0.08 & 0.11 & 0.53 & 0.27 & 0.00 \\
\hline 28 & 0.08 & 0.11 & 0.53 & 0.27 & 0.00 \\
\hline 29 & 0.08 & 0.11 & 0.53 & 0.28 & 0.00 \\
\hline 30 & 0.10 & 0.08 & 0.59 & 0.23 & 0.00 \\
\hline 31 & 0.10 & 0.12 & 0.60 & 0.18 & 0.01 \\
\hline 32 & 0.07 & 0.19 & 0.55 & 0.19 & 0.05 \\
\hline 35 & 0.07 & 0.19 & 0.56 & 0.18 & 0.04 \\
\hline 36 & 0.06 & 0.17 & 0.56 & 0.21 & 0.03 \\
\hline 37 & 0.07 & 0.17 & 0.56 & 0.21 & 0.02 \\
\hline 38 & 0.07 & 0.15 & 0.55 & 0.23 & 0.02 \\
\hline 39 & 0.10 & 0.11 & 0.60 & 0.19 & 0.00 \\
\hline 40 & 0.10 & 0.10 & 0.59 & 0.21 & 0.00 \\
\hline 41 & 0.05 & 0.22 & 0.53 & 0.20 & 0.04 \\
\hline
\end{tabular}


Table 1 (Contd.)

\begin{tabular}{|c|c|c|c|c|c|}
\hline Spectrum & $\mathrm{Cr}$ & $\mathrm{Ni}$ & $\mathrm{Fe}$ & $\mathrm{Zr}$ & $\mathrm{U}$ \\
\hline \hline 42 & 0.05 & 0.18 & 0.54 & 0.22 & 0.02 \\
\hline 43 & 0.08 & 0.11 & 0.58 & 0.23 & 0.00 \\
\hline 44 & 0.09 & 0.12 & 0.57 & 0.23 & 0.00 \\
\hline 45 & 0.06 & 0.22 & 0.57 & 0.14 & 0.09 \\
\hline 47 & 0.06 & 0.18 & 0.65 & 0.12 & 0.06 \\
\hline
\end{tabular}

Note: (Atomic fractions, normalized to $\mathrm{Cr}+\mathrm{Ni}+\mathrm{Fe}+\mathrm{Zr}=1$ for comparison with other samples; total of atomic fractions may be $>1$ )

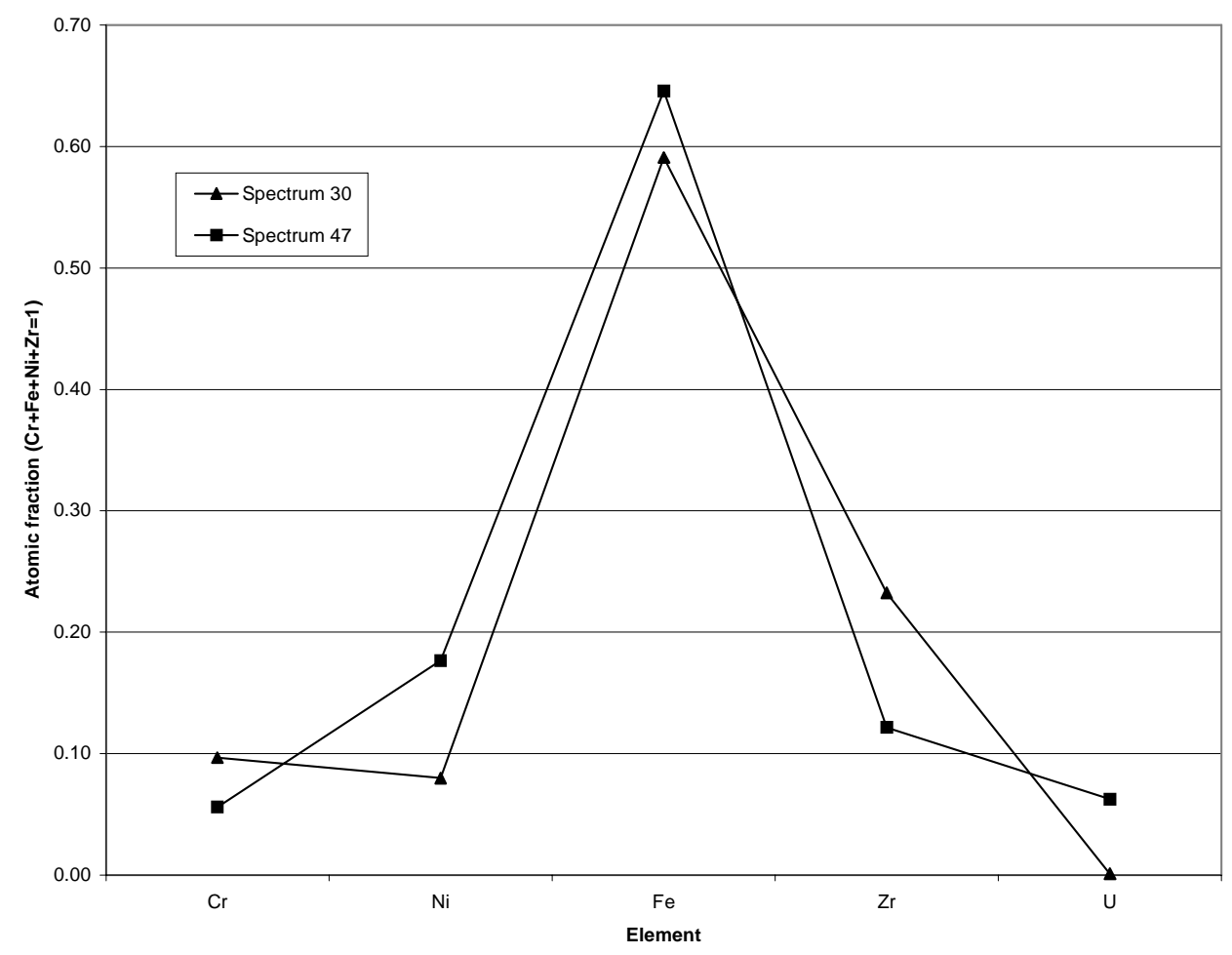

Fig. 7. Compositional Variation in $\mathrm{Fe}_{23} \mathrm{Zr}_{6}$ Structure, $5 \mathrm{U}$ 


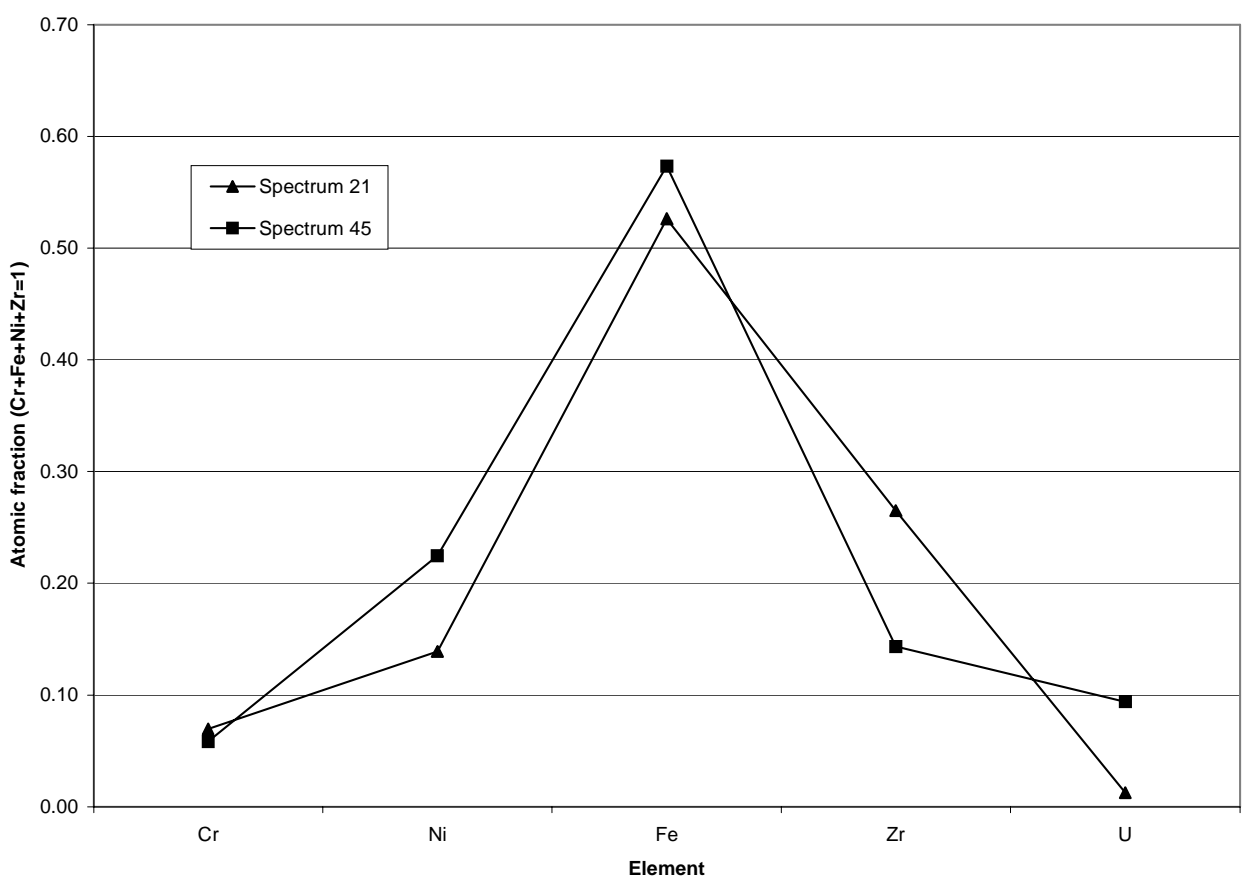

Fig. 8. Compositional Variation in $\mathrm{C} 15 \mathrm{Fe}_{2} \mathrm{Zr}$ Structure, $5 \mathrm{U}$

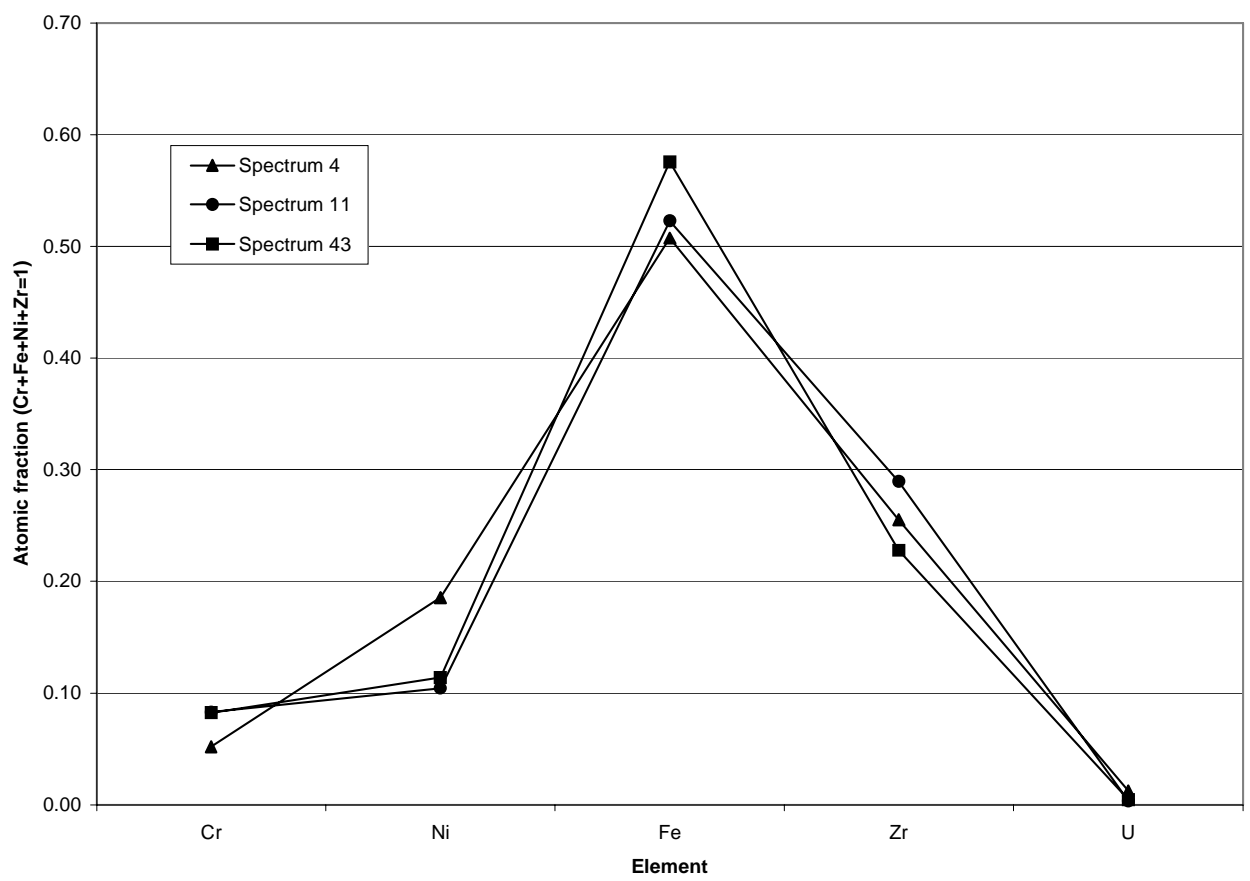

Fig. 9. Compositional Variation in $\mathrm{C} 36 \mathrm{Fe}_{2} \mathrm{Zr}$ Structure, $5 \mathrm{U}$ 
Many images from intermetallics in 5U show closely spaced planar defects, sometimes occurring in more than one crystallographic orientation within the same area (Fig. 10). The defects end at dislocations, some occurring at intersections with other defects (arrows in Fig 11) Changes in contrast at dislocations indicate elastic strain. There are no detectable changes in crystallographic orientation, diffraction patterns, or chemical compositions associated with the defects. Thus, the defects are not twin boundaries, grain or subgrain boundaries, thin precipitates with compositions significantly different from those of the host crystal, or phase boundaries. All of these characteristics are consistent with the identification of the defects as stacking faults representing local offsets in the layered structure.

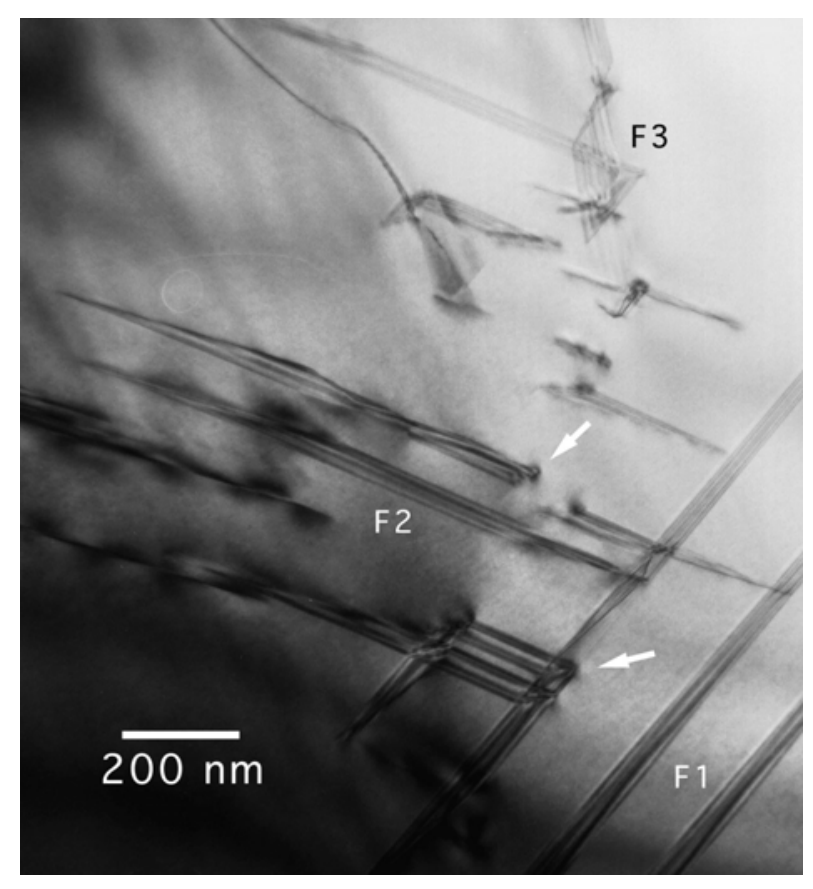

Fig. 10. F1, F2, and F3 Indicate Examples of Three Orientations of Stacking Faults in 5U, Spectrum 16 Includes One of the Defects Shown Here, Spectrum 15 is From A Nearby Defect-Free Area

Two EDX spectra were collected from steels in 5U. Both show distinct Mo peaks, one has a small Ar peak, and neither has detectable U. Because the steel was clearly not a major actinidebearing phase, no attempt was made to determine whether it was ferrite or austenite.

\section{$3.211 \mathrm{U}:$}

Transmission electron microscope data from intermetallic phases in $11 \mathrm{U}$ include over 65 zoneaxis diffraction patterns and 55 EDX spectra, representing more than 20 areas. Three EDX traverses, each containing multiple spectra from different parts of the same crystal to explore intracrystalline chemical variability, were also collected. 
Intermetallics with both $\mathrm{C} 15 \mathrm{Fe}_{2} \mathrm{Zr}$ and $\mathrm{C} 36 \mathrm{Fe}_{2} \mathrm{Zr}$ structures were observed in 11U. Diffraction patterns from $\mathrm{C} 36 \mathrm{Fe}_{2} \mathrm{Zr}$ from appropriate orientations show closely spaced reflections corresponding to interplanar spacings of $1.6 \mathrm{~nm}$ (Fig. 11). Strong streaks through these reflections (at arrows in Fig. 11) indicate stacking disorder. Transitions between the $\mathrm{C} 15 \mathrm{Fe}_{2} \mathrm{Zr}$ and $\mathrm{C}_{6} \mathrm{Fe}_{2} \mathrm{Zr}$ structures are sharp and follow planar defects (Fig. 12).

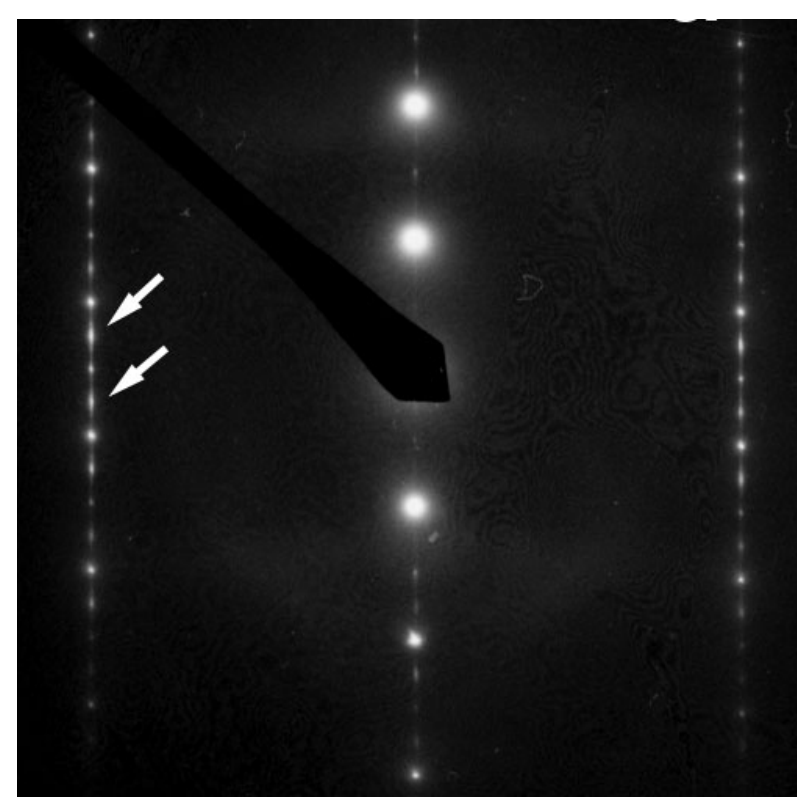

Fig. 11. Diffraction Pattern, $\mathrm{C}_{6} \mathrm{Fe}_{2} \mathrm{Zr}$ Structure 11U, EDX Spectrum 41 is From This Area

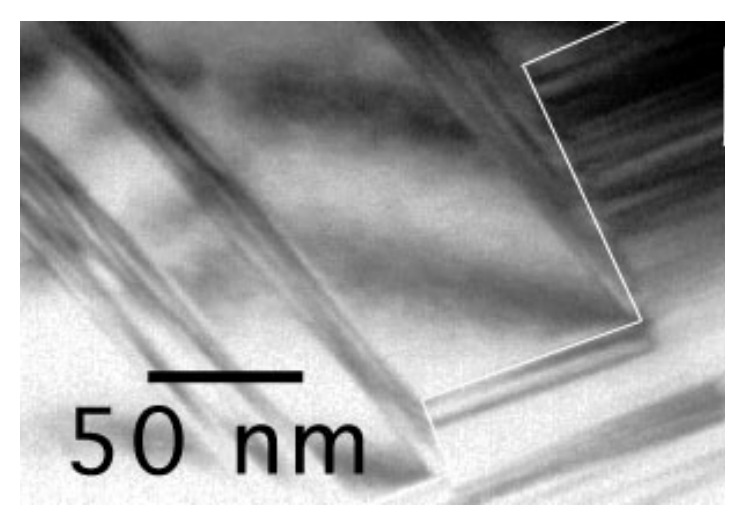

Fig. 12. White Line Follows Transition between C15 $\mathrm{Fe}_{2} \mathrm{Zr}$ (left) and $\mathrm{C} 36 \mathrm{Fe}_{2} \mathrm{Zr}$ (right) Structures $11 \mathrm{U}$

Energy-dispersive X-ray spectra from material with the $\mathrm{C} 36 \mathrm{Fe}_{2} \mathrm{Zr}$ structure are relatively homogeneous and contain at most 5 at\% U (Fig. 13). In contrast, spectra from $\mathrm{C} 15 \mathrm{Fe}_{2} \mathrm{Zr}$ display significant variation in major-element concentrations (Fig. 14), and $U$ concentrations from 2 to 20 at\% (Table 2). There is little difference in composition between $\mathrm{C} 36 \mathrm{Fe}_{2} \mathrm{Zr}$ and adjacent areas 
of $\mathrm{C} 15 \mathrm{Fe}_{2} \mathrm{Zr}$ (compare spectra 3 and 5, which are just outside the left and right edges of Fig. 12, for example).

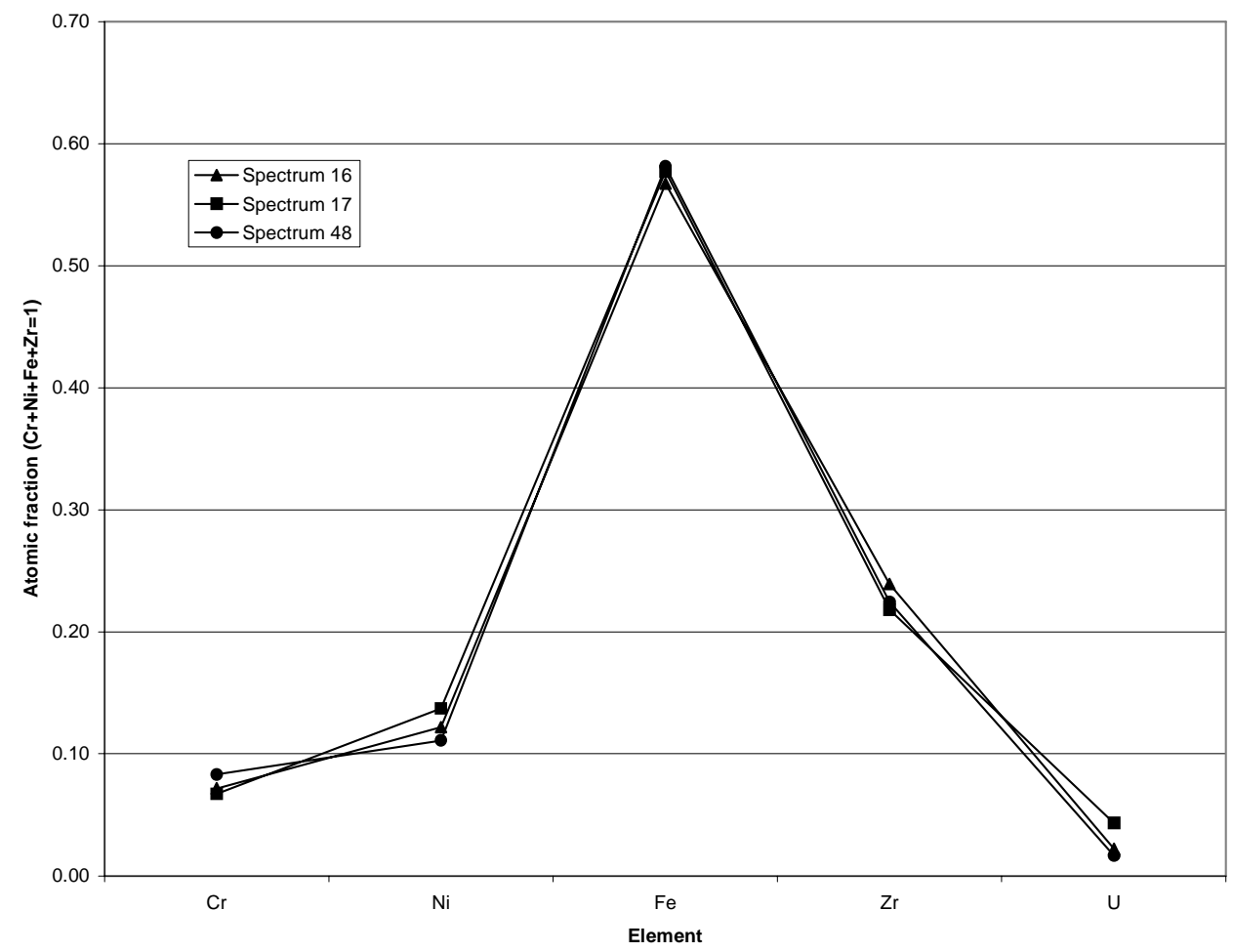

Fig. 13. Compositional variation in $\mathrm{C} 36 \mathrm{Fe}_{2} \mathrm{Zr}$ Structure, $11 \mathrm{U}$ 


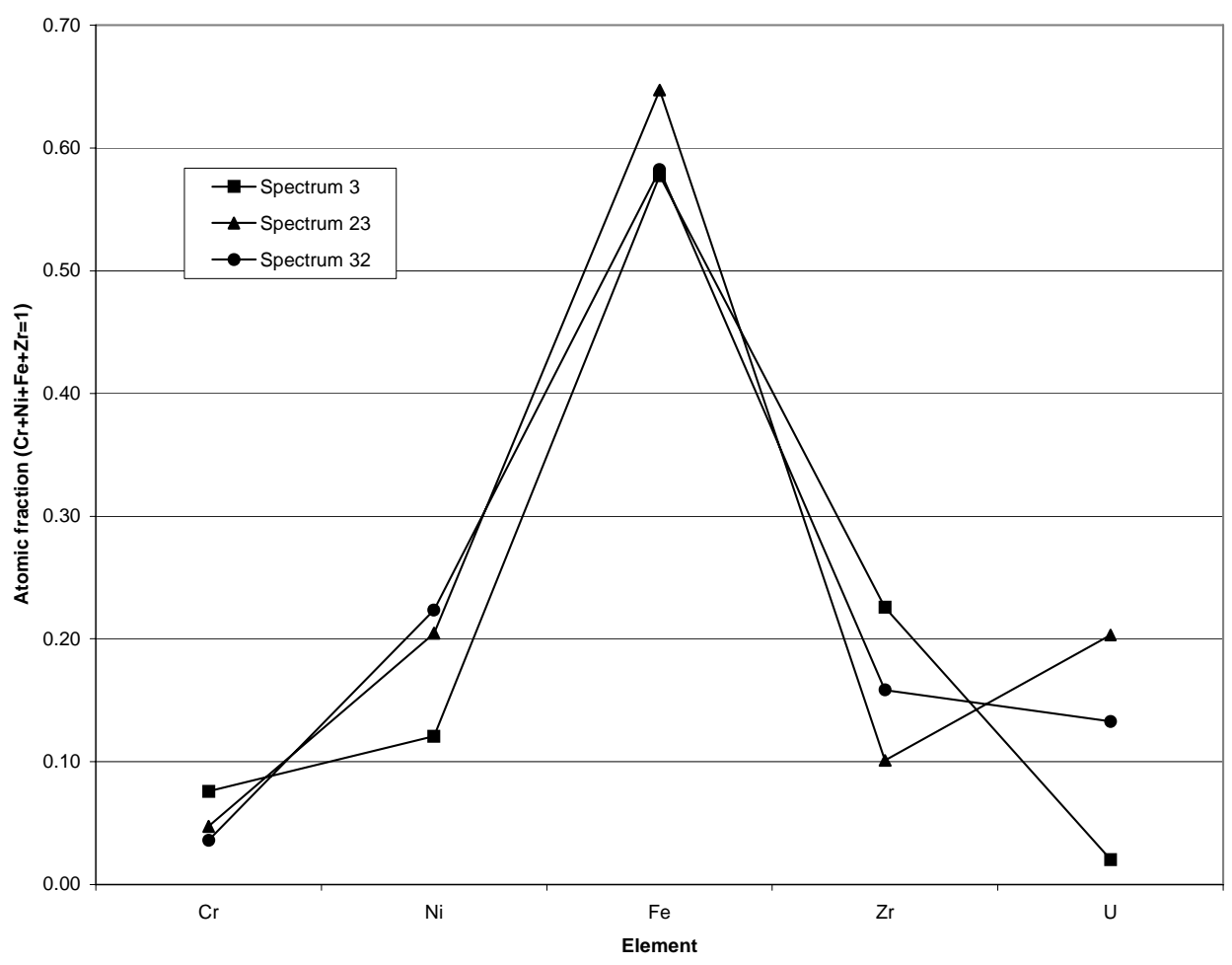

Fig. 14. Compositional variation in $\mathrm{C} 15 \mathrm{Fe}_{2} \mathrm{Zr}$ Structure, $11 \mathrm{U}$

Table 2. EDX Data from Intermetallic Materials in 11U

\begin{tabular}{|c|c|c|c|c|c|}
\hline Spectrum & $\mathrm{Cr}$ & $\mathrm{Ni}$ & $\mathrm{Fe}$ & $\mathrm{Zr}$ & $\mathrm{U}$ \\
\hline \hline 2 & 0.06 & 0.19 & 0.57 & 0.18 & 0.06 \\
\hline 3 & 0.08 & 0.12 & 0.58 & 0.23 & 0.02 \\
\hline 5 & 0.08 & 0.12 & 0.58 & 0.22 & 0.02 \\
\hline 8 & 0.05 & 0.17 & 0.57 & 0.21 & 0.06 \\
\hline 9 & 0.06 & 0.15 & 0.57 & 0.21 & 0.05 \\
\hline 10 & 0.06 & 0.14 & 0.57 & 0.23 & 0.04 \\
\hline 11 & 0.07 & 0.13 & 0.57 & 0.23 & 0.03 \\
\hline 12 & 0.07 & 0.13 & 0.57 & 0.23 & 0.03 \\
\hline 13 & 0.07 & 0.13 & 0.57 & 0.23 & 0.02 \\
\hline 14 & 0.08 & 0.12 & 0.57 & 0.22 & 0.02 \\
\hline 15 & 0.08 & 0.12 & 0.57 & 0.24 & 0.02 \\
\hline
\end{tabular}


Table 2. (Contd.)

\begin{tabular}{|c|c|c|c|c|c|}
\hline Spectrum & $\mathrm{Cr}$ & $\mathrm{Ni}$ & $\mathrm{Fe}$ & $\mathrm{Zr}$ & $\mathrm{U}$ \\
\hline 16 & 0.07 & 0.12 & 0.57 & 0.24 & 0.02 \\
\hline 17 & 0.07 & 0.14 & 0.58 & 0.22 & 0.04 \\
\hline 18 & 0.07 & 0.14 & 0.61 & 0.19 & 0.06 \\
\hline 19 & 0.05 & 0.16 & 0.60 & 0.19 & 0.08 \\
\hline 20 & 0.04 & 0.20 & 0.58 & 0.19 & 0.09 \\
\hline 21 & 0.05 & 0.20 & 0.61 & 0.14 & 0.14 \\
\hline 22 & 0.05 & 0.20 & 0.62 & 0.14 & 0.16 \\
\hline 23 & 0.05 & 0.20 & 0.65 & 0.10 & 0.20 \\
\hline 24 & 0.05 & 0.19 & 0.63 & 0.13 & 0.18 \\
\hline 25 & 0.06 & 0.19 & 0.62 & 0.14 & 0.15 \\
\hline 26 & 0.05 & 0.18 & 0.61 & 0.15 & 0.15 \\
\hline 27 & 0.06 & 0.18 & 0.61 & 0.15 & 0.13 \\
\hline 28 & 0.06 & 0.17 & 0.59 & 0.18 & 0.09 \\
\hline 29 & 0.05 & 0.17 & 0.59 & 0.19 & 0.08 \\
\hline 30 & 0.06 & 0.17 & 0.61 & 0.16 & 0.11 \\
\hline 31 & 0.04 & 0.18 & 0.60 & 0.17 & 0.10 \\
\hline 32 & 0.04 & 0.22 & 0.58 & 0.16 & 0.13 \\
\hline 34 & 0.06 & 0.15 & 0.58 & 0.21 & 0.06 \\
\hline 35 & 0.08 & 0.11 & 0.58 & 0.23 & 0.02 \\
\hline 36 & 0.07 & 0.13 & 0.57 & 0.24 & 0.03 \\
\hline 37 & 0.06 & 0.12 & 0.58 & 0.23 & 0.03 \\
\hline 38 & 0.08 & 0.11 & 0.57 & 0.23 & 0.02 \\
\hline 39 & 0.08 & 0.11 & 0.57 & 0.23 & 0.02 \\
\hline 40 & 0.05 & 0.18 & 0.62 & 0.15 & 0.15 \\
\hline 41 & 0.08 & 0.11 & 0.58 & 0.23 & 0.02 \\
\hline 42 & 0.05 & 0.20 & 0.64 & 0.11 & 0.19 \\
\hline 43 & 0.04 & 0.19 & 0.60 & 0.16 & 0.14 \\
\hline 45 & 0.08 & 0.12 & 0.58 & 0.22 & 0.02 \\
\hline
\end{tabular}


Table 2. (Contd.)

\begin{tabular}{|c|c|c|c|c|c|}
\hline Spectrum & $\mathrm{Cr}$ & $\mathrm{Ni}$ & $\mathrm{Fe}$ & $\mathrm{Zr}$ & $\mathrm{U}$ \\
\hline \hline 46 & 0.08 & 0.11 & 0.58 & 0.22 & 0.02 \\
\hline 47 & 0.09 & 0.11 & 0.58 & 0.22 & 0.02 \\
\hline 48 & 0.08 & 0.11 & 0.58 & 0.22 & 0.02 \\
\hline 49 & 0.08 & 0.11 & 0.58 & 0.23 & 0.02 \\
\hline 50 & 0.08 & 0.11 & 0.58 & 0.23 & 0.02 \\
\hline 51 & 0.08 & 0.11 & 0.58 & 0.22 & 0.02 \\
\hline 52 & 0.07 & 0.13 & 0.59 & 0.22 & 0.03 \\
\hline 54 & 0.07 & 0.17 & 0.60 & 0.16 & 0.10 \\
\hline 57 & 0.07 & 0.12 & 0.58 & 0.23 & 0.02 \\
\hline 58 & 0.06 & 0.15 & 0.57 & 0.22 & 0.05 \\
\hline 59 & 0.09 & 0.10 & 0.58 & 0.23 & 0.01 \\
\hline 60 & 0.09 & 0.10 & 0.57 & 0.23 & 0.01 \\
\hline 61 & 0.07 & 0.12 & 0.58 & 0.23 & 0.03 \\
\hline 62 & 0.05 & 0.16 & 0.58 & 0.21 & 0.07 \\
\hline 63 & 0.06 & 0.16 & 0.59 & 0.19 & 0.07 \\
\hline 64 & 0.06 & 0.17 & 0.60 & 0.17 & 0.09 \\
\hline
\end{tabular}

Note: Atomic fractions, normalized to $\mathrm{Cr}+\mathrm{Ni}+\mathrm{Fe}+\mathrm{Zr}=1$ for comparison with other samples; total of atomic fractions may be $>1$ )

Keiser et al. observed low concentrations ( $\sim 1$ at\%) of Tc in $\mathrm{Fe}_{2} \mathrm{Zr}$-type intermetallic phases in SS-15Zr-2Tc [8]. Several EDX spectra were collected with long (1200 second) counting times to explore possible preferences of Tc for specific intermetallic structures. Although some of the spectra display what might be small $\mathrm{Tc} \mathrm{K}_{\alpha}$ peaks, the intensities of the peaks relative to the background did not increase with longer counting times; thus, these spectra do not allow determination of Tc concentrations or phase preferences.

Three EDX spectra were collected from steels in 11U. All show distinct Mo peaks, and most show small Tc peaks. One of the spectra has detectable $U$ (as well as significant concentrations of $\mathrm{Si}, \mathrm{Ar}$, and other elements suggesting that material from outside the sample was introduced during ion milling). The steel was clearly not a major actinide-bearing phase, and no attempt was made to determine whether it was ferritic or austenitic. 


\subsection{Np:}

Data from intermetallic phases in 2Np include approximately 75 zone-axis diffraction patterns, representing 12 symmetrically non-equivalent zone axes, 20 areas, and at least 7 crystals (depending on how twins are counted). All but one of the crystals was identified as having the $\mathrm{C} 15 \mathrm{Fe}_{2} \mathrm{Zr}$ structure. The remaining crystal is a grinding fragment embedded in epoxy in a bubble or crack in the original ingot. It has a large d-spacing that does not occur in the C14 $\mathrm{Fe}_{2} \mathrm{Zr}$, C15 $\mathrm{Fe}_{2} \mathrm{Zr}$, or $\mathrm{Fe}_{23} \mathrm{Zr}_{6}$ structure, but may be the $1.6 \mathrm{~nm}$ spacing in the $\mathrm{C}_{6} \mathrm{Fe}_{2} \mathrm{Zr}$ structure.

All of the EDX data from intermetallic phases in 2Np show low Np concentrations (e.g., Fig. 5a, Table 3). Figure 15 compares composition in a single crystal with the $\mathrm{C} 15 \mathrm{Fe}_{2} \mathrm{Zr}$ structure. (Fig. 15a) with the extreme compositions from all analyses from this sample (Fig. 15b). Spectra Fig. 15a were collected at approximately equally spaced points in the electron-transparent area where the edge of an ion-milled hole crosses a single crystal. Spectra 60 and 65, which have relatively high $\mathrm{Ni}$ and low Fe concentrations, were collected close to grain boundaries with adjacent crystals. The remaining spectra are farther from the edges of the crystal in the plane of the specimen; however, their distances from the edges of the crystal in the third dimension are unknown. The gap between spectra with high and low Ni/Fe ratios suggests a sharp chemical gradient within the same crystal structure.

Table 3. EDX Data from Intermetallic Materials in 2Np

\begin{tabular}{|c|c|c|c|c|c|c|}
\hline Spectrum & $\mathrm{Cr}$ & $\mathrm{Ni}$ & $\mathrm{Fe}$ & $\mathrm{Zr}$ & $\begin{array}{c}\text { Np/Zr } \\
\text { Intensity } \\
\text { Ratio }\end{array}$ & $\mathrm{Np}$ \\
\hline \hline 5 & 0.07 & 0.21 & 0.54 & 0.19 & 0.07 & 0.01 \\
\hline 9 & 0.07 & 0.22 & 0.52 & 0.19 & 0.09 & 0.01 \\
\hline 10 & 0.07 & 0.23 & 0.51 & 0.19 & 0.15 & 0.02 \\
\hline 20 & 0.05 & 0.29 & 0.46 & 0.20 & 0.15 & 0.02 \\
\hline 24 & 0.05 & 0.29 & 0.47 & 0.19 & 0.14 & 0.02 \\
\hline 26 & 0.06 & 0.26 & 0.53 & 0.15 & 0.13 & 0.01 \\
\hline 27 & 0.06 & 0.23 & 0.51 & 0.20 & 0.15 & 0.02 \\
\hline 29 & 0.06 & 0.26 & 0.49 & 0.20 & 0.13 & 0.01 \\
\hline 33 & 0.07 & 0.27 & 0.50 & 0.16 & 0.18 & 0.02 \\
\hline 37 & 0.06 & 0.28 & 0.47 & 0.19 & 0.14 & 0.02 \\
\hline 39 & 0.06 & 0.27 & 0.49 & 0.18 & 0.12 & 0.01 \\
\hline 41 & 0.06 & 0.21 & 0.51 & 0.22 & 0.05 & 0.01 \\
\hline 43 & 0.06 & 0.23 & 0.52 & 0.19 & 0.06 & 0.01 \\
\hline
\end{tabular}


Table 3. (Contd.)

\begin{tabular}{|c|c|c|c|c|c|c|}
\hline Spectrum & $\mathrm{Cr}$ & $\mathrm{Ni}$ & $\mathrm{Fe}$ & $\mathrm{Zr}$ & $\begin{array}{c}\mathrm{Np} / \mathrm{Zr} \\
\text { intensity ratio }\end{array}$ & $\mathrm{Np}$ \\
\hline 44 & 0.07 & 0.22 & 0.53 & 0.17 & 0.04 & 0.00 \\
\hline 45 & 0.05 & 0.29 & 0.46 & 0.20 & 0.07 & 0.01 \\
\hline 47 & 0.11 & 0.17 & 0.53 & 0.20 & 0.13 & 0.02 \\
\hline 48 & 0.06 & 0.23 & 0.51 & 0.20 & 0.07 & 0.01 \\
\hline 50 & 0.05 & 0.27 & 0.50 & 0.19 & 0.06 & 0.01 \\
\hline 51 & 0.05 & 0.24 & 0.50 & 0.21 & 0.06 & 0.01 \\
\hline 52 & 0.05 & 0.23 & 0.52 & 0.19 & 0.06 & 0.01 \\
\hline 53 & 0.06 & 0.22 & 0.54 & 0.18 & 0.07 & 0.01 \\
\hline 54 & 0.05 & 0.22 & 0.51 & 0.20 & 0.07 & 0.01 \\
\hline 55 & 0.05 & 0.25 & 0.51 & 0.19 & 0.07 & 0.01 \\
\hline 56 & 0.06 & 0.26 & 0.49 & 0.19 & 0.06 & 0.01 \\
\hline 57 & 0.05 & 0.24 & 0.50 & 0.20 & 0.06 & 0.01 \\
\hline 58 & 0.05 & 0.27 & 0.49 & 0.20 & 0.06 & 0.01 \\
\hline 59 & 0.06 & 0.22 & 0.52 & 0.19 & 0.07 & 0.01 \\
\hline 60 & 0.05 & 0.29 & 0.41 & 0.24 & 0.12 & 0.01 \\
\hline 61 & 0.06 & 0.24 & 0.46 & 0.24 & 0.10 & 0.01 \\
\hline 62 & 0.06 & 0.22 & 0.48 & 0.24 & 0.12 & 0.01 \\
\hline 63 & 0.07 & 0.21 & 0.47 & 0.25 & 0.11 & 0.01 \\
\hline 64 & 0.07 & 0.22 & 0.47 & 0.23 & 0.12 & 0.01 \\
\hline 65 & 0.05 & 0.28 & 0.43 & 0.24 & 0.15 & 0.01 \\
\hline 66 & 0.06 & 0.28 & 0.43 & 0.24 & 0.11 & 0.01 \\
\hline 67 & 0.06 & 0.22 & 0.47 & 0.25 & 0.11 & 0.01 \\
\hline 68 & 0.08 & 0.20 & 0.49 & 0.23 & 0.11 & 0.01 \\
\hline 70 & 0.06 & 0.23 & 0.49 & 0.22 & 0.11 & 0.01 \\
\hline 71 & 0.06 & 0.23 & 0.50 & 0.21 & 0.11 & 0.01 \\
\hline
\end{tabular}

Note: (Cr, Ni, Fe, and $\mathrm{Zr}$ are atomic fractions from the Link Isis software, normalized to a total of $1 . \mathrm{Np} / \mathrm{Zr}$ intensity ratio is the ratio of the intensities of $\mathrm{Np} \mathrm{L}_{\alpha}$ and $\mathrm{Zr} \mathrm{K}_{\alpha}$ characteristic X-rays, assuming a linear background model for each peak. See Section 2.0 for determination of atomic fraction of Np.) 


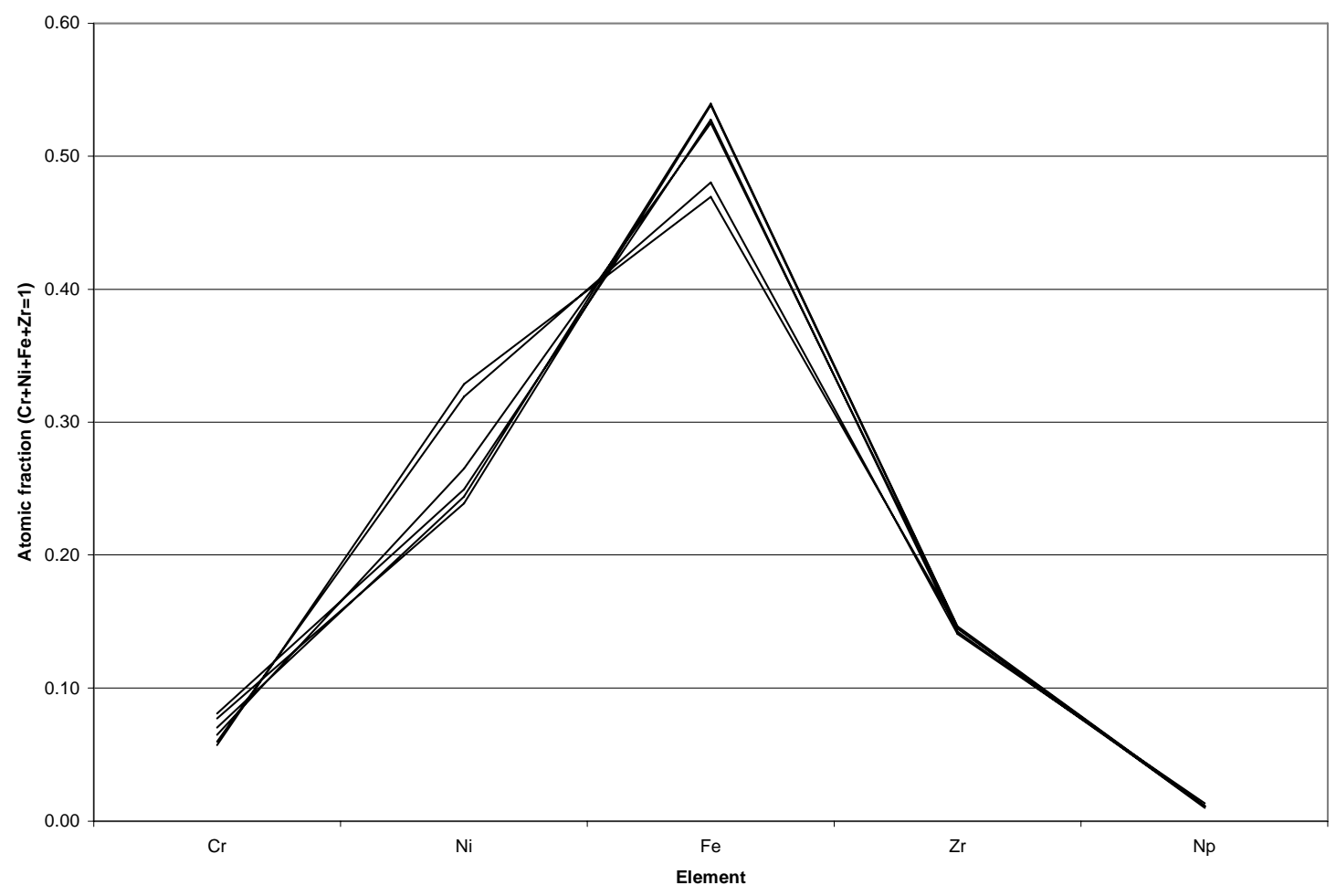

Fig. 15a. Compositional Variation within a Single Crystal of 2Np, Spectra 60-65

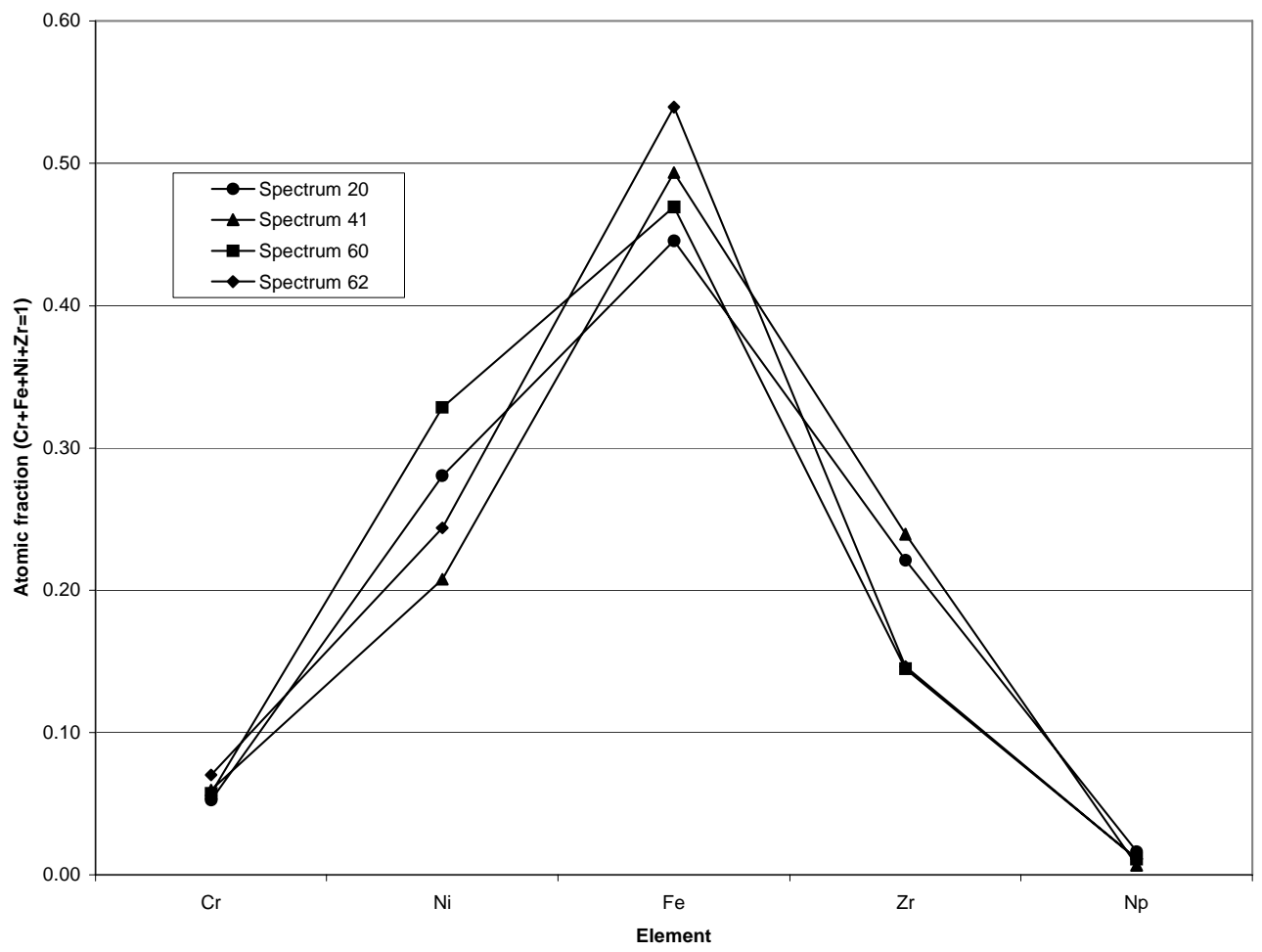

Fig. 15b. Compositional Variation in all analyses from the $\mathrm{C} 15 \mathrm{Fe}_{2} \mathrm{Zr}$ structure, $2 \mathrm{~Np}$ 
Transmission electron microscope images show that intermetallic areas in $2 \mathrm{~Np}$ are commonly defect-free. However, one crystal has plentiful twins with widths as small as $1 \mathrm{~nm}$ (Fig. 16). This crystal also has a small area that produces reflections corresponding to an interplanar spacing of $1.2 \mathrm{~nm}$, suggesting a three-layer structure distinct from the $\mathrm{C} 15 \mathrm{Fe}_{2} \mathrm{Zr}$ structure in the surrounding material.

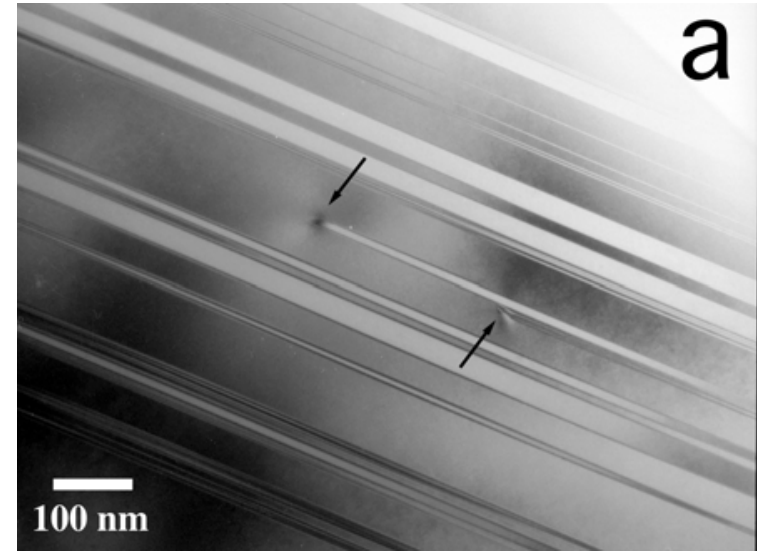

Twins of Variable Widths, C15 $\mathrm{Fe}_{2} \mathrm{Zr}$ Structure, 2Np (arrows show twin ending at dislocations)

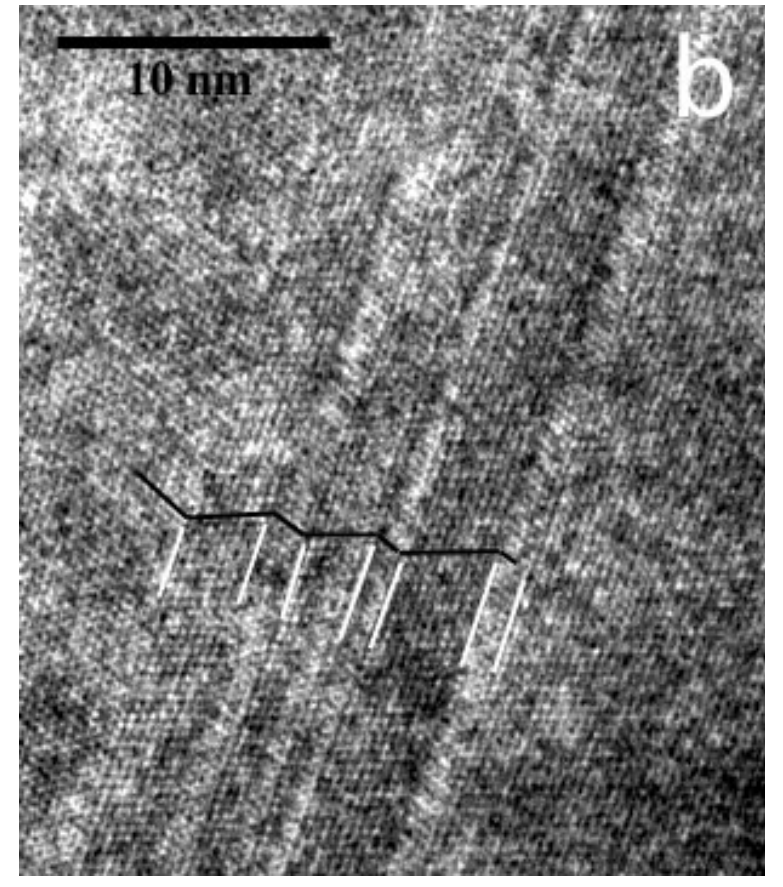

High-resolution TEM Image of Narrow Twins C15 $\mathrm{Fe}_{2} \mathrm{Zr}$ Structure, 2Np (white lines indicate twin boundaries; the black line follows a single lattice fringe across several twins; lattice-fringe spacing is $\sim 0.4 \mathrm{~nm}$ )

Fig. 16. Twins in $\mathrm{C} 15 \mathrm{Fe}_{2} \mathrm{Zr}$ Structure, $2 \mathrm{~Np}$

Energy dispersive X-ray and diffraction analyses show that $2 \mathrm{~Np}$ contains both ferrite and austenite. Unlike the intermetallic phases, both kinds of steel contain detectable Mo, and neither contains significant quantities of actinides. Images show that steels commonly have high dislocation densities.

\section{$3.410 \mathrm{Pu}$ :}

Data from 10Pu include 75 zone-axis diffraction patterns representing approximately 40 areas. The data represent at least five materials: two Fe-Zr intermetallics with distinctly different concentrations of zirconium, small high-Pu inclusions in one of the intermetallics, a high-Pu material with significant Mo, and steel. 
Table 4. EDX Data from 10Pu (excluding steel and the high-Pu, high-Mo material)

\begin{tabular}{|c|c|c|c|c|c|c|c|}
\hline Spectrum & $\begin{array}{l}\text { Major- } \\
\text { Element } \\
\text { Total } \\
\text { Counts }\end{array}$ & $\mathrm{Cr}$ & $\mathrm{Ni}$ & $\mathrm{Fe}$ & $\mathrm{Zr}$ & $\begin{array}{c}\mathrm{Pu} / \mathrm{Zr} \\
\text { Intensity } \\
\text { Ratio }\end{array}$ & $\mathrm{Pu}$ \\
\hline 9 & 49998 & 0.05 & 0.02 & 0.14 & 0.78 & 0.14 & 0.22 \\
\hline 11 & 16692 & 0.05 & 0.02 & 0.14 & 0.78 & 0.10 & 0.17 \\
\hline 13 & 636050 & 0.06 & 0.17 & 0.53 & 0.24 & 0.33 & 0.05 \\
\hline 14 & 6351 & 0.09 & 0.06 & 0.36 & 0.50 & 2.12 & 0.70 \\
\hline 15 & 2526 & 0.06 & 0.03 & 0.23 & 0.67 & 0.03 & 0.04 \\
\hline 16 & 4112 & 0.03 & 0.02 & 0.13 & 0.81 & 0.03 & 0.08 \\
\hline 22 & 5406 & 0.09 & 0.17 & 0.56 & 0.18 & 0.74 & 0.08 \\
\hline 23 & 4964 & 0.10 & 0.15 & 0.58 & 0.18 & 1.35 & 0.13 \\
\hline 24 & 8778 & 0.07 & 0.14 & 0.55 & 0.24 & 0.69 & 0.11 \\
\hline 26 & 3844 & 0.11 & 0.18 & 0.55 & 0.16 & 0.83 & 0.07 \\
\hline 27 & 3529 & 0.11 & 0.16 & 0.59 & 0.14 & 2.15 & 0.16 \\
\hline 28 & 4416 & 0.07 & 0.18 & 0.59 & 0.16 & 1.34 & 0.12 \\
\hline 30 & 9380 & 0.05 & 0.27 & 0.49 & 0.19 & 1.39 & 0.16 \\
\hline 32 & 2669 & 0.05 & 0.05 & 0.33 & 0.58 & 0.45 & 0.27 \\
\hline 33 & 2489 & 0.13 & 0.18 & 0.59 & 0.10 & 3.81 & 0.20 \\
\hline 34 & 1509 & 0.07 & 0.18 & 0.53 & 0.23 & 0.89 & 0.13 \\
\hline 36 & 1270 & 0.10 & 0.23 & 0.48 & 0.20 & 0.30 & 0.04 \\
\hline 37 & 2324 & 0.05 & 0.19 & 0.51 & 0.26 & 0.41 & 0.08 \\
\hline 38 & 29656 & 0.05 & 0.20 & 0.54 & 0.20 & 0.41 & 0.05 \\
\hline 40 & 16974 & 0.05 & 0.22 & 0.55 & 0.18 & 0.50 & 0.05 \\
\hline 41 & 39890 & 0.06 & 0.20 & 0.54 & 0.21 & 0.39 & 0.05 \\
\hline 42 & 65395 & 0.06 & 0.20 & 0.54 & 0.21 & 0.32 & 0.04 \\
\hline 43 & 76137 & 0.05 & 0.21 & 0.52 & 0.22 & 0.30 & 0.04 \\
\hline 44 & 27108 & 0.05 & 0.19 & 0.55 & 0.21 & 0.32 & 0.04 \\
\hline 45 & 31208 & 0.05 & 0.20 & 0.54 & 0.21 & 0.37 & 0.05 \\
\hline
\end{tabular}


Table 4. (Contd.)

\begin{tabular}{|c|c|c|c|c|c|c|c|}
\hline Spectrum & $\begin{array}{c}\text { Major- } \\
\text { Element } \\
\text { Total } \\
\text { Counts }\end{array}$ & $\mathrm{Cr}$ & $\mathrm{Ni}$ & $\mathrm{Fe}$ & $\mathrm{Zr}$ & $\begin{array}{c}\mathrm{Pu} / \mathrm{Zr} \\
\text { Intensity } \\
\text { Ratio }\end{array}$ & $\mathrm{Pu}$ \\
\hline \hline 46 & 37846 & 0.04 & 0.22 & 0.53 & 0.21 & 0.34 & 0.05 \\
\hline 51 & 250049 & 0.07 & 0.20 & 0.52 & 0.21 & 0.56 & 0.08 \\
\hline 52 & 318448 & 0.06 & 0.04 & 0.18 & 0.72 & 0.19 & 0.21 \\
\hline 53 & 535276 & 0.05 & 0.23 & 0.50 & 0.22 & 0.42 & 0.06 \\
\hline 54 & 110204 & 0.07 & 0.14 & 0.54 & 0.24 & 0.16 & 0.03 \\
\hline 55 & 222875 & 0.01 & 0.01 & 0.06 & 0.92 & 0.01 & 0.07 \\
\hline 56 & 206271 & 0.05 & 0.29 & 0.51 & 0.16 & 1.69 & 0.15 \\
\hline
\end{tabular}

Note: (Major-element total counts is the sum of counts that the Link Isis software determined were in the Cr $\mathrm{K}_{\alpha}$, $\mathrm{Ni} \mathrm{K} \mathrm{K}_{\alpha}, \mathrm{Fe} \mathrm{K}_{\alpha}$, and $\mathrm{Zr} \mathrm{K} \mathrm{K}_{\alpha}$ peaks. $\mathrm{Cr}, \mathrm{Ni}$, and Fe are atomic fractions based on intensities calculated by the Link Isis software. $\mathrm{Zr}$ and $\mathrm{Pu}$ are atomic fractions calculated from intensities based on subtraction of the spontaneously-generated X-ray spectrum and linear background and an extrapolated K-factor for $\mathrm{Pu}$. Pu/Zr intensity ratio is the ratio of the intensities of $\mathrm{Pu} \mathrm{L}_{\alpha}$ and $\mathrm{Zr} \mathrm{K} \mathrm{K}_{\alpha}$ characteristic X-rays. Atomic fractions are normalized to $\mathrm{Cr}+\mathrm{Ni}+\mathrm{Fe}+\mathrm{Zr}=1$.)

Most of the data from intermetallic materials in $10 \mathrm{Pu}$ are from material with $10-25 \mathrm{at} \% \mathrm{Zr}$ and the $\mathrm{C} 15 \mathrm{Fe}_{2} \mathrm{Zr}$ structure (Table 4). Images show a characteristic mottled appearance indicating structural or compositional variation on a scale of a few $\mathrm{nm}$ or tens of $\mathrm{nm}$. Twinning is common (Fig. 17), and planar defects ending at dislocations were observed. Relative concentrations of major elements are somewhat variable, and all EDX spectra from this phase show detectable $\mathrm{Pu}$ (e.g., Fig. 18 and Fig. 19). 


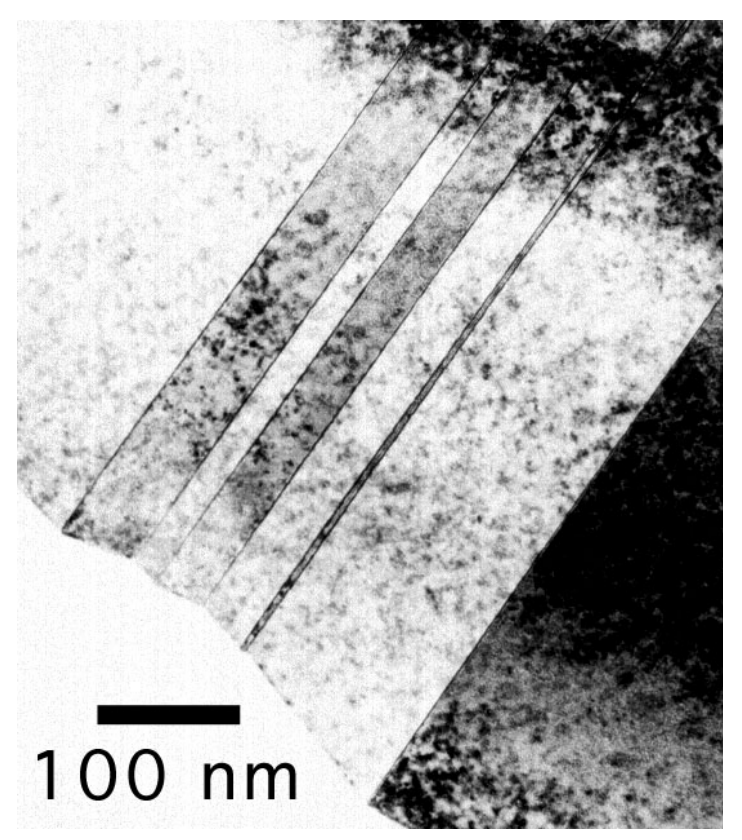

Fig. 17. Twinning in $\mathrm{C} 15 \mathrm{Fe}_{2} \mathrm{Zr}$ Intermetallic Phase (note characteristic mottled appearance, the offset grain boundary at the left ends of the twins accommodates shearing strain associated with formation of the twins)

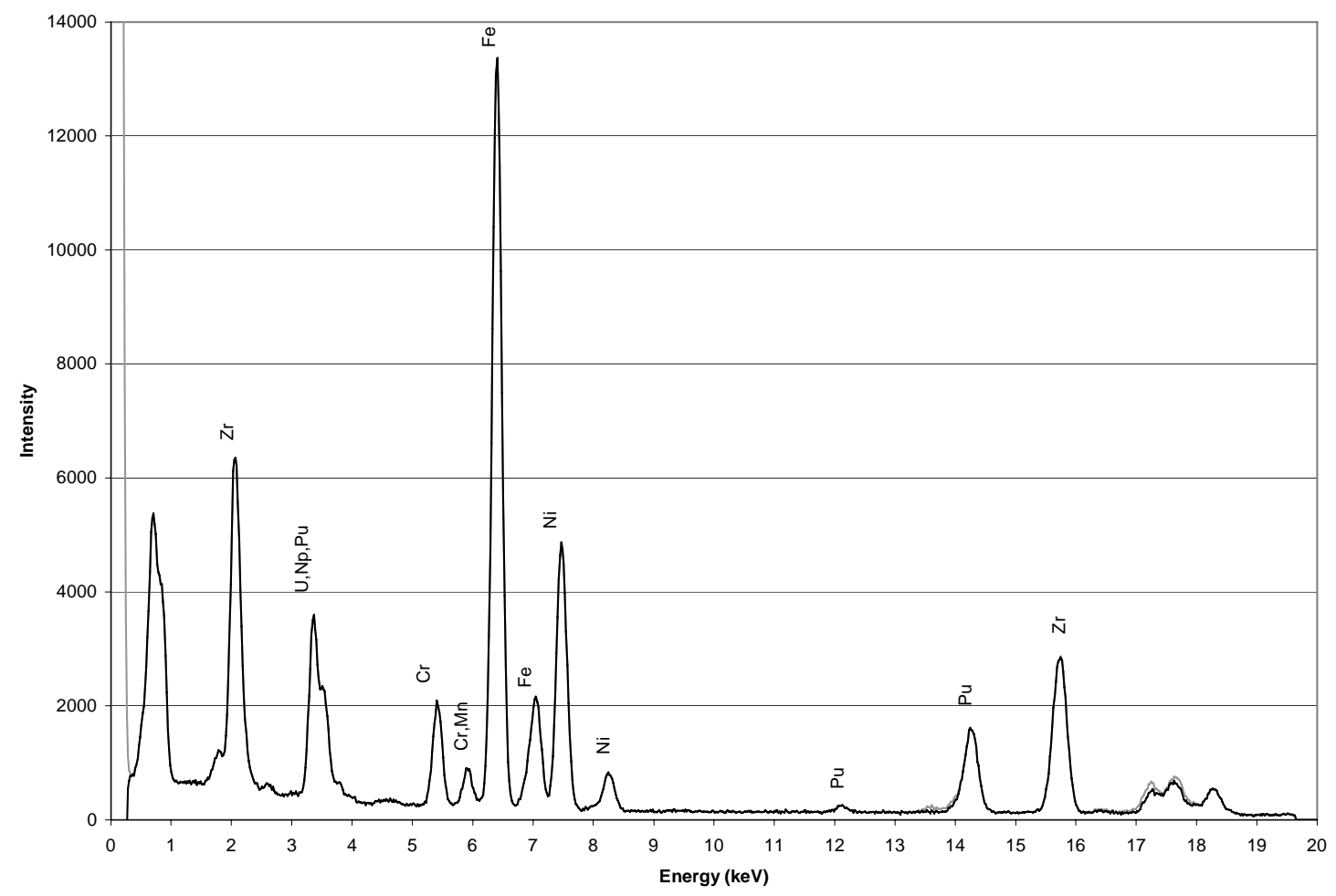

Fig. 18. $\mathrm{C} 15 \mathrm{Fe}_{2} \mathrm{Zr}$, Spectrum 51, $10 \mathrm{Pu}$ 


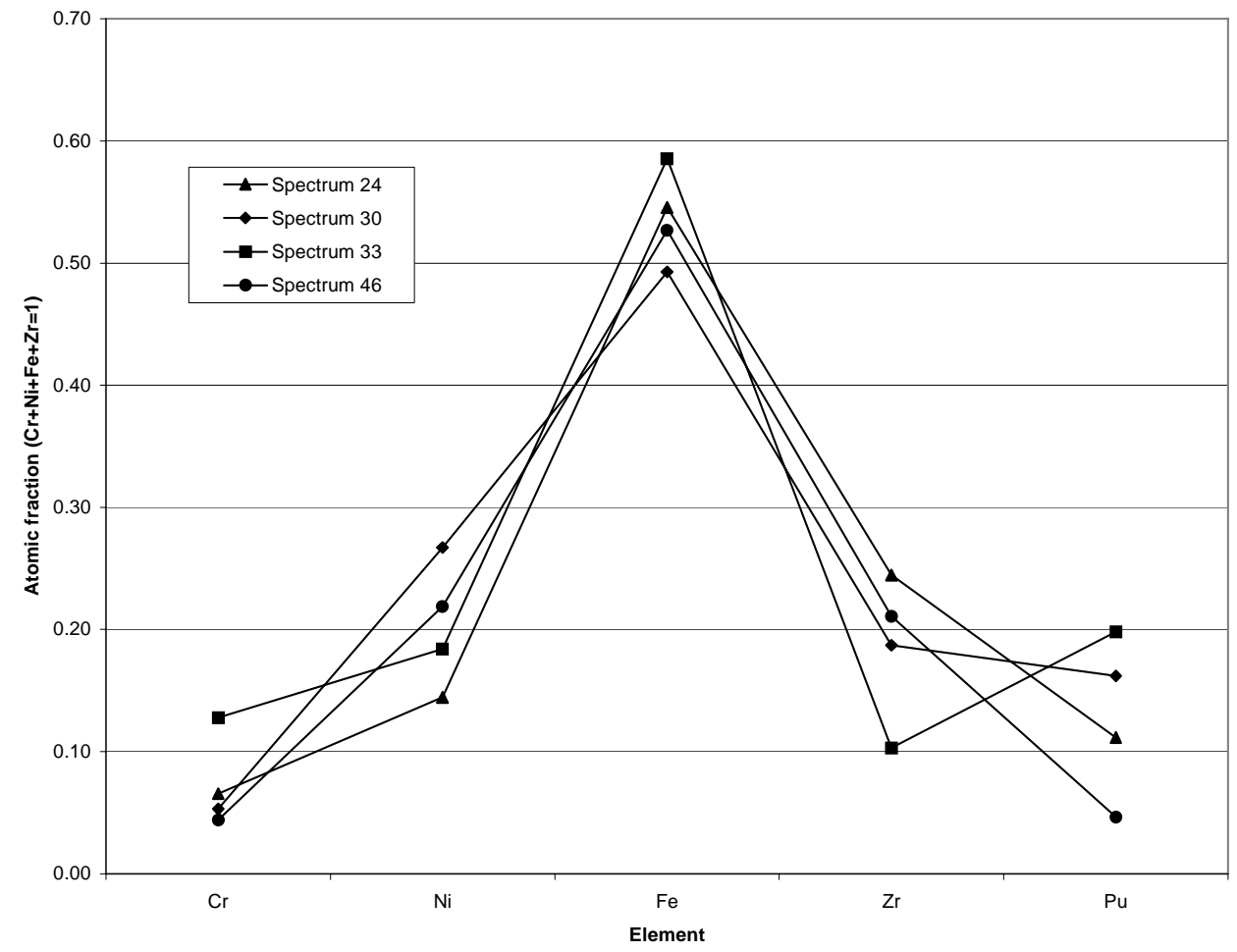

Fig. 19. $\mathrm{C} 15 \mathrm{Fe}_{2} \mathrm{Zr}, 10 \mathrm{Pu}$

The remaining data from intermetallic materials show $\mathrm{Zr}$ concentrations greater than 75\% (Fig. 20 and Fig. 21). Corresponding diffraction patterns are consistent with cubic $\mathrm{FeZr}_{2}$ or $\mathrm{FeZr}_{3}$. Those corresponding to Spectrum $55(\tilde{90}$ at $\% \mathrm{Zr})$ also permit identification as orthorhombic $\mathrm{FeZr}_{4}$ (a material with a poorly known composition that was identified during crystallization of amorphous Fe-Zr alloys but does not appear in the Fe-Zr phase diagram [15]). With the possible exception of the material in Spectrum 55, the high-Zr material has been identified as $\mathrm{FeZr}_{3}$ based on comparison between its $\mathrm{Zr}$ content and those reported for $\mathrm{FeZr}_{2}$ and $\mathrm{FeZr}_{3}$ ( 67 and 75 at\%, respectively [19]). Small, rounded inclusions with a high Pu content were observed at a subgrain boundary in the $\mathrm{FeZr}_{3}$ (Fig. 22, Fig. 23, Fig. 21). 


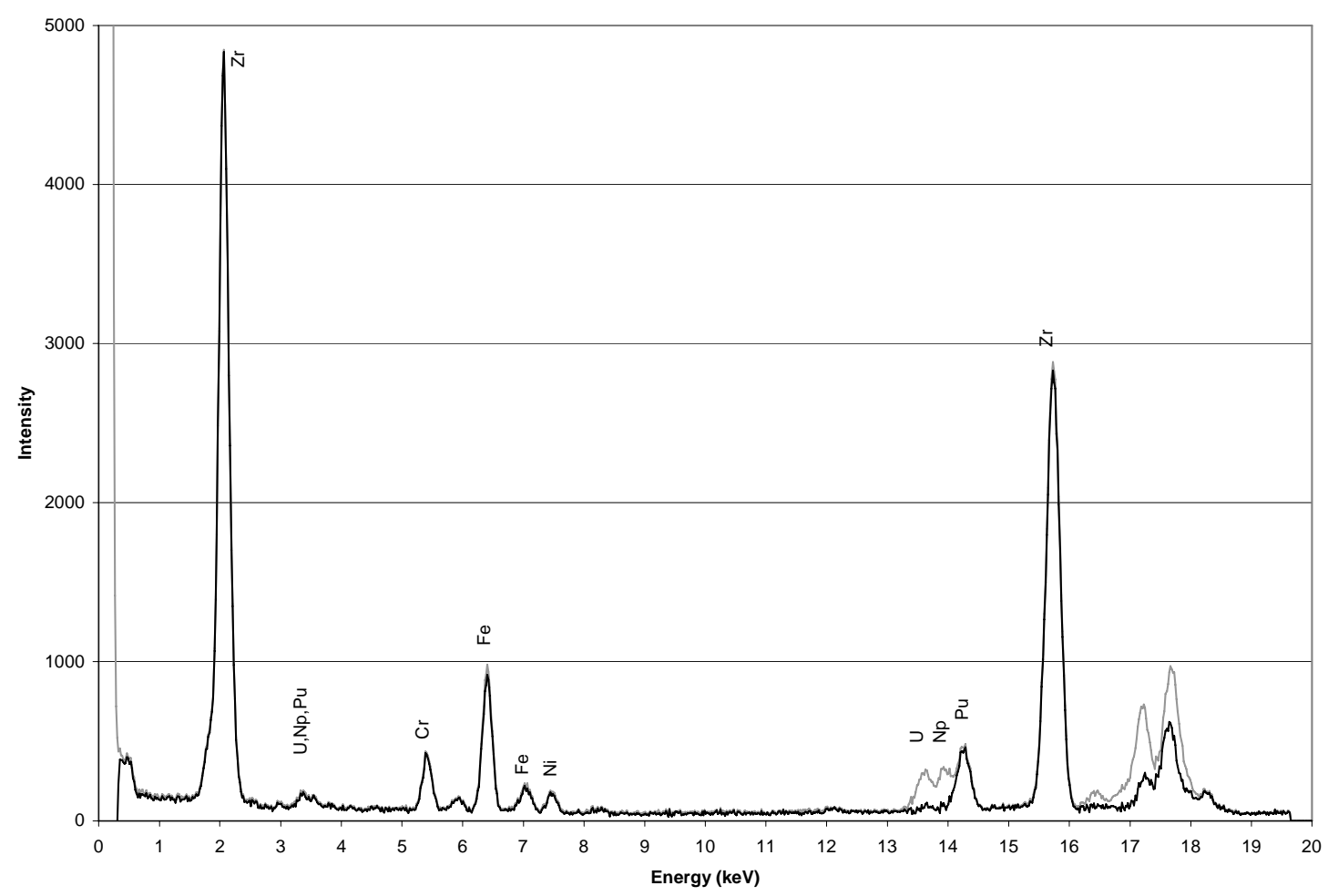

Fig. 20. $\mathrm{FeZr}_{3}$ with $\mathrm{Cr}, \mathrm{Ni}$, and $\mathrm{Pu}$, Spectrum 9, $10 \mathrm{Pu}$

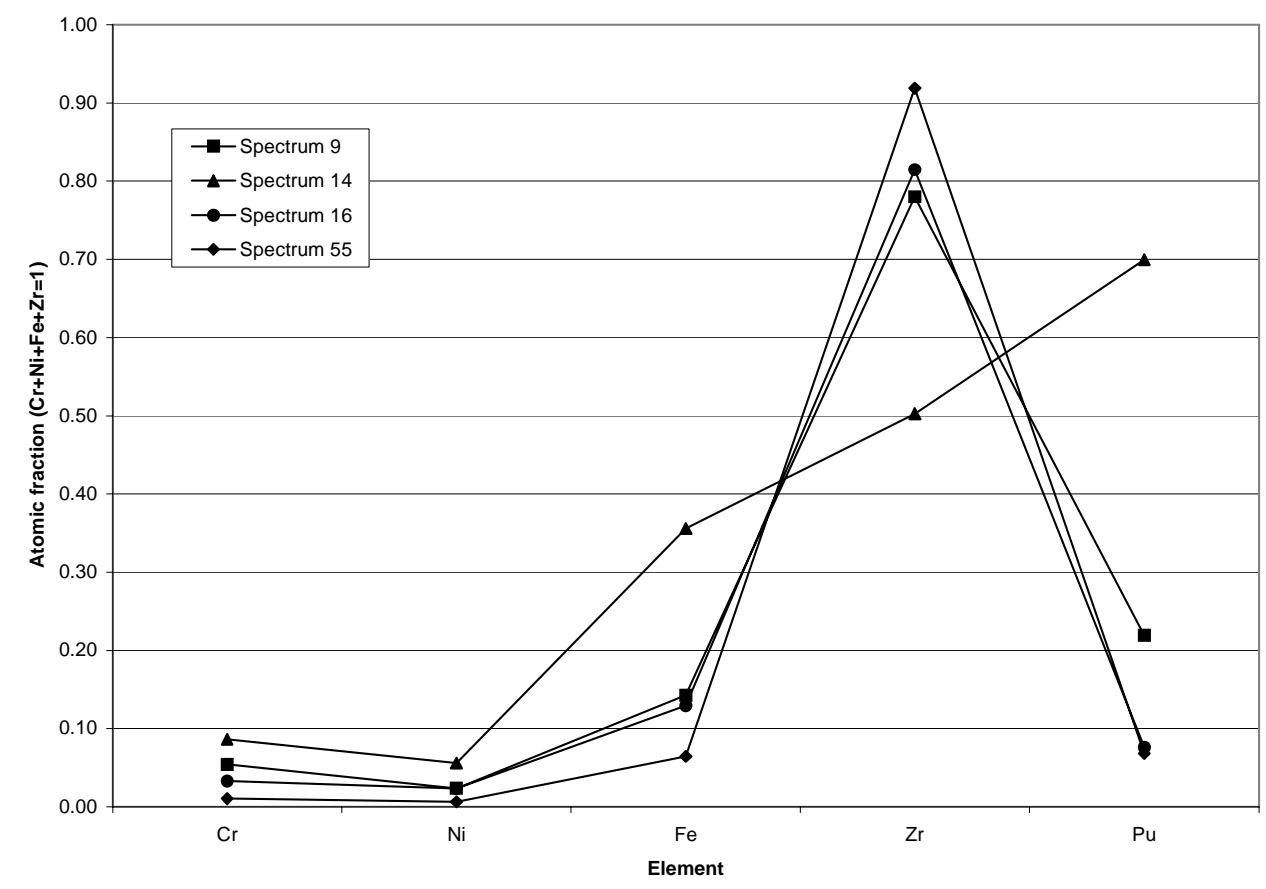

Fig. 21. High-Zr Phases, $10 \mathrm{Pu}$ 


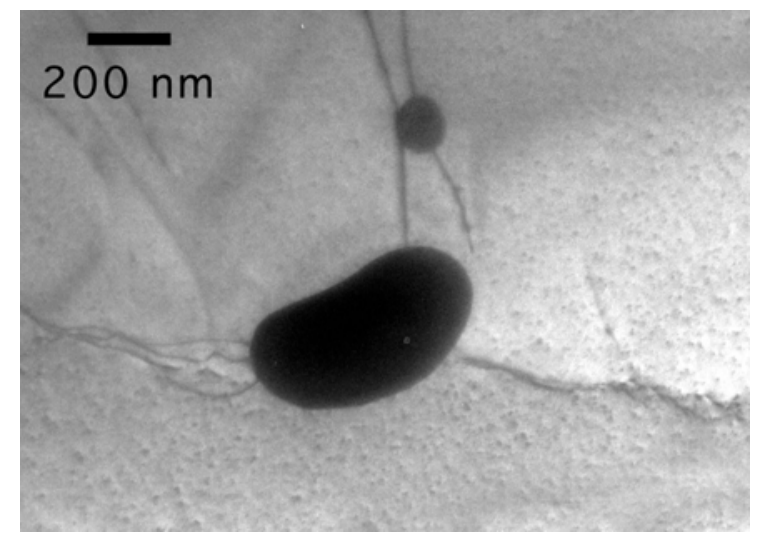

Fig. 22. High-Pu Inclusions at a Subgrain Boundary in $\mathrm{FeZr}_{3}, 10 \mathrm{Pu}$

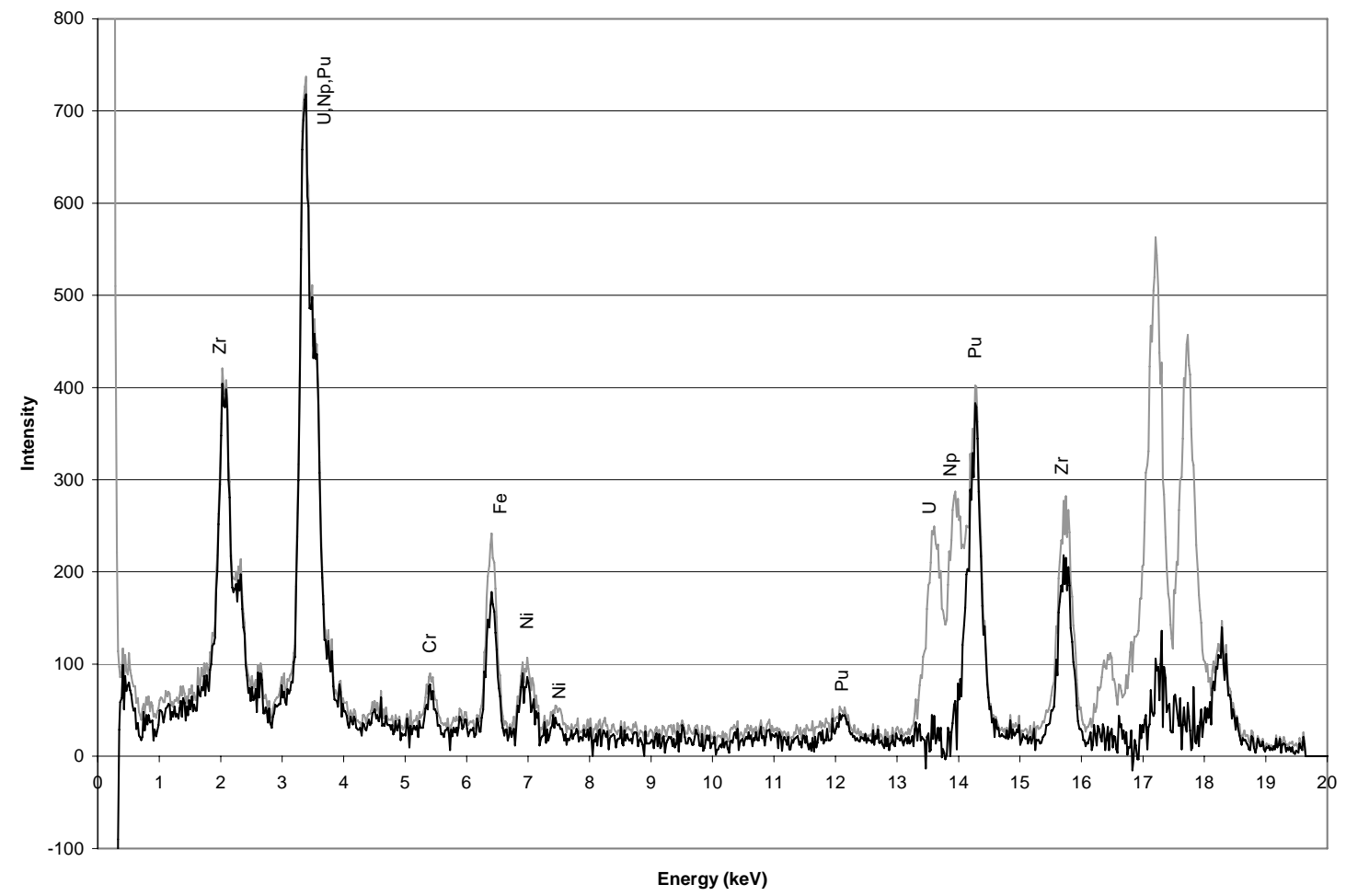

Fig. 23. High-Pu Inclusions in $\mathrm{FeZr}_{3}$ (probably including characteristic X-rays from adjacent $\mathrm{FeZr}_{3}$ crystals) Spectrum 14, $10 \mathrm{Pu}$

Two crystals from a high-Pu material that also contains significant Mo were observed. Both crystals were adjacent to high-Zr materials; one occurred at the edge of a bubble. Spectrum 57 (Fig. 24) shows a peak at $15 \mathrm{keV}$, which may be the $\mathrm{Y} \mathrm{K}_{\alpha}$ peak (14.955 keV). Confirmation by identification of other $\mathrm{Y}$ peaks was not possible because of overlaps with elements known to be present. Chemical analyses for the three spectra collected from this phase are in Table 5. 
Table 5. EDX Data from the High-Pu, High-Mo Material in 10Pu

\begin{tabular}{|c|c|c|c|c|c|c|c|}
\hline Spectrum & $\mathrm{Cr}$ & $\mathrm{Fe}$ & $\mathrm{Ni}$ & $\mathrm{Zr}$ & $\mathrm{Mo}$ & $\begin{array}{c}\text { Pu /Zr } \\
\text { Intensity Ratio }\end{array}$ & $\mathrm{Pu}$ \\
\hline \hline 10 & 0.08 & 0.23 & 0.04 & 0.34 & 0.08 & 1.48 & 0.23 \\
\hline 17 & 0.08 & 0.29 & 0.04 & 0.00 & 0.19 & 1067.50 & 0.40 \\
\hline 57 & 0.04 & 0.22 & 0.02 & 0.08 & 0.23 & 11.68 & 0.41 \\
\hline
\end{tabular}

Note: $\mathrm{Cr}, \mathrm{Ni}, \mathrm{Fe}$, and $\mathrm{Mo}$ are atomic fractions based on intensities calculated by the Link Isis software. $\mathrm{Zr}$ and $\mathrm{Pu}$ are atomic fractions calculated from intensities based on subtraction of the spontaneously-generated X-ray spectrum and linear background and an extrapolated $\mathrm{K}$-factor for $\mathrm{Pu}$. $\mathrm{Pu} / \mathrm{Zr}$ intensity ratio is the ratio of the intensities of $\mathrm{Pu} \mathrm{L}{ }_{\alpha}$ and $\mathrm{Zr} \mathrm{K} \mathrm{K}_{\alpha}$ characteristic X-rays. Atomic fractions are normalized to $\mathrm{Cr}+\mathrm{Ni}+\mathrm{Fe}+\mathrm{Zr}+\mathrm{Mo}+\mathrm{Pu}=1$.

Spectra 17 and 57 are from the same crystal. Spectrum 10 was collected at the edge of a bubble. Steel spectra collected from similar bubble edges include anomalously high concentrations of $\mathrm{Zr}$; thus, differences between spectrum 10 and the others may not be an accurate representation of chemical variability in the material. Spectrum 57 may include $\sim 1 \% \mathrm{Y}$.

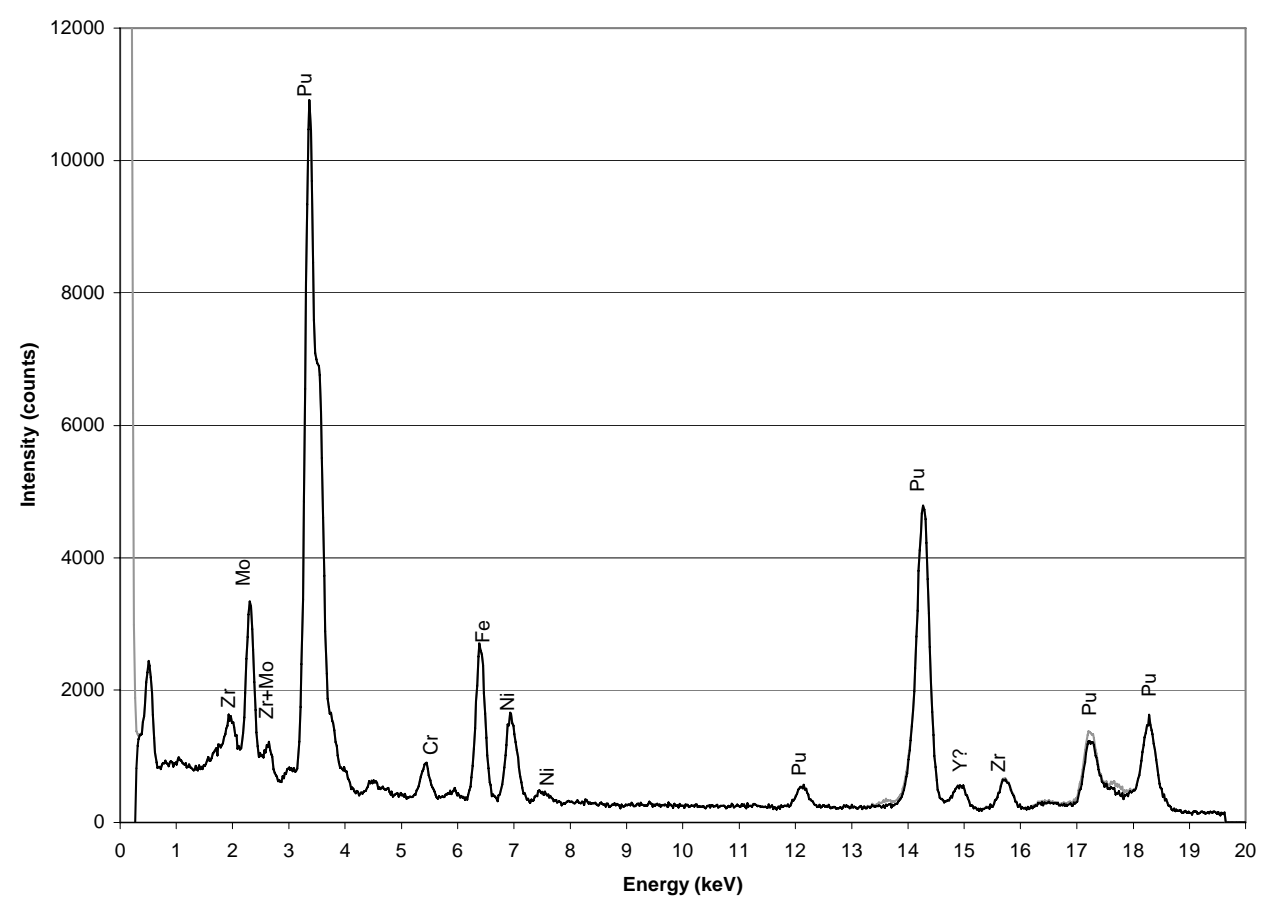

Fig. 24. High-Pu Phase, Spectrum 57, 10 Pu

Table 6 lists the specimen tilts, the two largest interplanar spacings, and the angle between them for zone-axis diffraction patterns from the high-Pu material. The Fe-Pu phase diagram shows three intermetallic phases with $>5$ at\% $\mathrm{Fe}$ and $<85$ at\% $\mathrm{Pu}: \alpha-\mathrm{Fe}_{2} \mathrm{Pu}$ (isostructural with $\mathrm{C} 15$ $\mathrm{Fe}_{2} \mathrm{Zr}$ ), $\beta$ - $\mathrm{Fe}_{2} \mathrm{Pu}$ (isostructural with $\mathrm{C} 36 \mathrm{Fe}_{2} \mathrm{Zr}$ ), and $\gamma-\mathrm{Fe}_{2} \mathrm{Zr}$ (structure unknown), all of which have limited composition ranges with $\sim 33 \% \mathrm{Pu}$ [21]. The interplanar spacing ratios and angles in 
Table 6 suggest that this is not a cubic crystal; thus, it cannot be $\alpha-\mathrm{Fe}_{2} \mathrm{Pu}$. Identification as $\beta-\mathrm{Fe}_{2} \mathrm{Pu}$ is also unlikely, as it would produce readily identifiable diffraction patterns similar to those from C36 $\mathrm{Fe}_{2} \mathrm{Zr}$. Thus, it seems likely that this material is either metastable or a stable ternary (Mo-Fe-Pu) compound. Further characterization is not currently planned.

Table 6. Zone-Axis Diffraction Data from the High-Pu, High-Mo Material in $10 \mathrm{Pu}$

\begin{tabular}{|c|c|c|c|c|c|c|}
\hline $\begin{array}{l}\text { Negative } \\
\text { Number }\end{array}$ & $\alpha$-Tilt & $\beta$-Tilt & $\begin{array}{c}\text { Largest } \\
\text { d-Spacing } \\
\text { (nm) }\end{array}$ & $\begin{array}{c}\text { Second } \\
\text { Largest } \\
\text { d-Spacing } \\
\text { (nm) }\end{array}$ & $\begin{array}{c}\text { Spacing } \\
\text { Ratio }\end{array}$ & $\begin{array}{c}\text { Interplanar } \\
\text { Angle } \\
\text { (degrees) }\end{array}$ \\
\hline DJ6989 & 18 & -3 & 0.35 & 0.19 & 1.8 & 74 \\
\hline DJ6992 & 5 & 8 & 0.31 & 0.25 & 1.3 & 89 \\
\hline DJ6993 & -10 & 3 & 0.31 & 0.31 & 1.0 & 78 \\
\hline DJ6994 & -20 & 10 & 0.24 & 0.20 & 1.3 & 79 \\
\hline DJ6995 & -29 & 17 & 0.35 & 0.25 & 1.4 & 70 \\
\hline DJ6996 & -7 & -20 & 0.35 & 0.31 & 1.1 & 64 \\
\hline DJ6997 & 10 & -8 & 0.35 & 0.25 & 1.4 & 70 \\
\hline
\end{tabular}

Note: $\alpha$-tilt and $\beta$-tilt are the specimen-holder tilt angles at which each negative was recorded. $\alpha$-tilt is parallel to the rotation axis of the holder; $\beta$-tilt is perpendicular. Largest and second-largest d-spacings and interplanar angle are the two largest lattice-plane spacings producing reflections in this diffraction pattern and the angle between them. Spacing ratio is the ratio of the largest and second-largest d-spacings. Estimated errors are $\pm 5^{\circ}$ away from a perfect zone-axis orientation for $\alpha$-tilt and $\beta$-tilt, $\pm 5 \%$ for $\mathrm{d}$-spacings, and $\pm 2^{\circ}$ for interplanar angles.

Strongly exposed diffraction patterns from the high-Pu material and most crystals of the adjacent high-Zr materials have several rings whose radii do not match spacings of reflections in the single-crystal patterns, indicating the presence of a nanocrystalline material distinct from that in the single-crystal patterns. The material has not been identified but contributes to the EDX spectra from the unknown phase, all but one spectrum from $\mathrm{FeZr}_{3}$, and perhaps the spectrum from the high-Pu inclusions in the $\mathrm{FeZr}_{3}$.

The Fe-Zr phase diagram has a eutectic composition at 91 at\% Fe, and stable phases in Fe-Zr alloys with bulk compositions $>66$ at\% Fe are $\alpha-F e, F_{2} Z r$, and $\mathrm{Fe}_{23} \mathrm{Zr}_{6}$ (e.g., [15, 19, 22]). Previous SEM and neutron-diffraction observations of SS-15Zr suggest a similar eutectic. Thus, the high-Zr phases observed here probably represent an area of incomplete mixing when the sample ingot was cast. The Y observed in one EDX spectrum from the high-Pu material suggests a possible reaction involving the crucible. These phenomena are believed to be consequences of the small size of the experimental ingot studied here and the location of the sample near the 
outside of the ingot. Thus, the high-Zr material and the adjacent high-Pu materials are probably not representative of common phases to be expected in production ingots of SS-15Zr.

Twelve EDX spectra and thirteen diffraction patterns were collected from steels in nine areas of the $10 \mathrm{Pu}$ specimens. Many of these areas are at the edges of holes with thick, irregular or lobate edges, apparently occurring where the ion-milled surfaces intersected bubbles or cracks formed during casting of the ingot. EDX spectra from these areas included significant concentrations of $\mathrm{Zr}$ and $\mathrm{Pu}$, probably reflecting inclusion of characteristic X-rays from the immediately adjacent thick areas at the edges of the bubbles or cracks. The remaining EDX spectra showed small Pu and $\mathrm{Zr}$ peaks, representing concentrations of at most a few atomic percent, but otherwise closely resembled EDX spectra from steels in the other specimens. Diffraction data indicated that three of the areas identified as steel have a ferritic structure; the structures of the other areas were not determined. Images of steel in $10 \mathrm{Pu}$ show high dislocation densities or heavy ion-milling damage.

\subsection{DISCUSSION AND CONCLUSIONS}

Previous neutron powder-diffraction studies of the $5 \mathrm{U}$ ingot reported that it contained $13 \%$ C36 $\mathrm{Fe}_{2} \mathrm{Zr}, 21 \% \mathrm{C} 15 \mathrm{Fe}_{2} \mathrm{Zr}$, and $17 \% \mathrm{Fe}_{23} \mathrm{Zr}_{6}$ [4]. Comparable data are not available for the other samples. These phase identifications are consistent with those reported here. Relative proportions of the phases observed in this study differ significantly from those reported by Keiser et al. [4], as well as between the two $5 \mathrm{U}$ samples studied here. Likely explanations for the different relative proportions include the small sample volume observable with TEM, the relatively large sizes of the crystals relative to the ion-milled holes, and the spatially inhomogeneous distribution of the different phases (e.g., Fig. 6). For similar reasons, the compositional variation observed in each structure in this study should be regarded as a minimum. It seems likely that greater variation would be found if more crystals or specimens were examined.

Although there is significant compositional variation within most of the phases studied here, a number of individual spectra match chemical compositions tabulated for the same specimens by Keiser et al. [4]. Elemental concentrations in the highest-U spectrum from C15 $\mathrm{Fe}_{2} \mathrm{Zr}$ in $11 \mathrm{U}$ are similar to those in the "U-rich Laves" phases observed by Keiser et al. [4] in both 5U and 11U (Fig. 2 and Fig. 14). Concentrations in the lowest-U C15 $\mathrm{Fe}_{2} \mathrm{Zr}$ spectrum and all spectra from C36 $\mathrm{Fe}_{2} \mathrm{Zr}$ in $11 \mathrm{U}$ match the "other Laves" phase observed in this sample by Keiser et al. [4] (Fig. 3 and Fig. 13). Similarly, concentrations in the highest-Ni spectra from 5U and lowest-Ni spectrum from the $\mathrm{C} 15 \mathrm{Fe}_{2} \mathrm{Zr}$ structure in Np are similar to the "other Laves" phases in SEM data from these samples [4] (compare Fig. 3 and Fig. 7-Fig. 9 for U, Fig. 3 and Fig. 15b for Np). Thus, it seems likely that areas of "U-rich Laves" in both $5 \mathrm{U}$ and $11 \mathrm{U}$ have the $\mathrm{C} 15 \mathrm{Fe}_{2} \mathrm{Zr}$ structure; the "other Laves” areas in these specimens could be either C36 Fe 2 Zr or C15 Fe 2 Zr. "Other Laves" areas in $2 \mathrm{~Np}$ are probably low-Ni regions of $\mathrm{C} 15 \mathrm{Fe}_{2} \mathrm{Zr}$. 
It has been stated that the main compositional difference between $\mathrm{C} 15$ and $\mathrm{C} 36 \mathrm{Fe}_{2} \mathrm{Zr}$ phases in pure SS-15Zr is the Ni/Cr ratio, which is $\sim 1.5$ for C36 $\mathrm{Fe}_{2} \mathrm{Zr}$ and $>2.5$ for C15 $\mathrm{Fe}_{2} \mathrm{Zr}$ [7]. Energydispersive X-ray analyses carried out during a previous TEM study of SS-15Zr-5U-2Tc [4] were consistent with these results. Major-element concentrations in this study confirm that the Ni/Cr ratio is generally lower in $\mathrm{C} 36 \mathrm{Fe}_{2} \mathrm{Zr}$ than in $\mathrm{C} 15 \mathrm{Fe}_{2} \mathrm{Zr}$. However, compositions of both phases are variable, and there is no sharp distinction in $\mathrm{Ni} / \mathrm{Cr}$ ratios between the two phases. (Compare Spectra 3 and 5 in Table 2, which are from adjacent regions with C15 and C36 Fe 2 Zr structures, respectively. Both have a $\mathrm{Ni} / \mathrm{Cr}$ ratio of 1.5$)$.

Keiser et al. [4] suggested that U concentration gradients in SS-15Zr-5U-2Tc might reflect the presence of a series of related $\mathrm{Fe}_{2} \mathrm{Zr}$ polytypes, each with a different actinide concentration, and that the highest concentration of $U$ should occur in the $\mathrm{C} 15 \mathrm{Fe}_{2} \mathrm{Zr}$ structure because of its cubic character. The observed $U$ concentrations in $5 U$ and $11 U$ confirm that $U$ concentrations in the C15 $\mathrm{Fe}_{2} \mathrm{Zr}$ structure are generally higher than those in the C36 $\mathrm{Fe}_{2} \mathrm{Zr}$ structure, and a boundary separating regions of these two structures might appear as an actinide concentration gradient in SEM images. However, the data from $11 \mathrm{U}$ do not support the idea that compositional gradients reflect a series of polytypes if the concentration of $U$ is more than 5 at\% (the observed upper bound for $\mathrm{U}$ in the $\mathrm{C} 36 \mathrm{Fe}_{2} \mathrm{Zr}$ structure). Instead, almost all of the actinide concentration variation occurs within the $\mathrm{C} 15 \mathrm{Fe}_{2} \mathrm{Zr}$ structure, which can be both a "low-U" and "high-U" phase in the sense of Keiser et al. [4]. Thus, all of the high-actinide areas and some of the lowactinide ones in SEM images probably have the $\mathrm{C} 15 \mathrm{Fe}_{2} \mathrm{Zr}$ structure, and the observed smooth transitions between high and low actinide areas represent chemical gradients within the C15 structure.

The structures of the $\mathrm{Fe}_{2} \mathrm{Zr}$ polytypes represent different stacking orders of the same chemical building blocks. They are commonly described by analogy to close-packed structures of single atoms, although the actual units making up the layers are structurally complex [10]. The $\mathrm{MgZn}_{2}$ (C14) structure is hexagonal and has a two-layer stacking repeat (ABAB). The $\mathrm{MgCu}_{2}$ (C15) structure is cubic, with a three-layer repeat (ABCABC). The $\mathrm{MgNi}_{2}$ (C36) structure has a fourlayer repeat (ABACABAC) [9, 23, 24]. Shear transformations in these structures can lead to mechanical twinning and formation of stacking faults bounded by partial dislocations $[10,25]$.

Stacking faults were commonly observed in both U-bearing samples, but rarely seen in $10 \mathrm{Pu}$ and never in $2 \mathrm{~Np}$. Stacking faults and coherent twin planes are both low-energy defects relative to grain boundaries; however, the energy of a stacking fault is generally about twice that of a twin plane in a close-packed material [26]. Etching experiments exploiting increased dissolution at intersections between dislocations and material surfaces have been used to investigate deformation microstructures in a variety of materials (e.g., [27, 28]). Thus, the stacking faults and associated dislocations may contribute to an increased dissolution rate for both U samples.

The stacking faults and twinning in the $\mathrm{C} 15 \mathrm{Fe}_{2} \mathrm{Zr}$ structure are similar to those produced by deforming a Fe-10 at\% $\mathrm{Zr}$ alloy by a compressive strain of $\sim 47 \%$ at room temperature [25]. Although quantitative determinations of stacking-fault and dislocation densities were not attempted, dislocation densities in steels in some areas of the dimpled samples (11U and 10Pu) 
appeared generally lower than those in $5 \mathrm{U}$ and $2 \mathrm{~Np}$, which were prepared by glueing thin fragments to grids. Stacking faults appeared somewhat less commonly in $11 \mathrm{U}$ than in 5U, particularly in crystals near relatively undeformed steels. Thus, despite the high mechanical strength of SS-15Zr alloys $(0.2 \%$ yield stress is $\sim 680 \mathrm{MPa}[17,29])$, introduction of deformation microstructures during TEM sample preparation cannot be ruled out. Possible reasons why U-bearing samples tend to have more stacking faults than those with $\mathrm{Pu}$ or $\mathrm{Np}$ include differences in sample preparation and orientation of the specific crystals examined relative to the applied stress responsible for the deformation. Other reasons may include such materials characteristics as differences in stacking-fault energies and dislocation mobility.

Neutron-diffraction observations of $\mathrm{Fe}_{23} \mathrm{Zr}_{6}$ in $5 \mathrm{U}$ suggest that the effects of $\mathrm{U}$ are larger than would be expected from the low (1.7 at\%) U concentration determined by previous EDX analyses in an SEM [4]. The present study may explain this discrepancy: although $\mathrm{Fe}_{23} \mathrm{Zr}_{6}$ crystals with U concentrations comparable to those reported by Keiser et al. [4] were observed in back-scattered electron images and EDX spectra collected with the TEM, others have significantly higher concentrations of $\mathrm{U}$.

The present data indicate that $\mathrm{C} 15 \mathrm{Fe}_{2} \mathrm{Zr}$ is a major $\mathrm{U}$ - and $\mathrm{Pu}$-bearing phase. If the assertion of Abraham and Richardson [7] that $\mathrm{C} 15 \mathrm{Fe}_{2} \mathrm{Zr}$ and $\mathrm{C} 36 \mathrm{Fe}_{2} \mathrm{Zr}$ structures can be distinguished by their Ni/Cr ratio holds true for Np-bearing samples, the "high-actinide" phase of Keiser et al. [4] in $2 \mathrm{~Np}$ also has the $\mathrm{C} 15 \mathrm{Fe}_{2} \mathrm{Zr}$ structure. Thus, it seems likely that differences in dissolution behavior between $\mathrm{U}$ and $\mathrm{Pu}$, and probably also between $\mathrm{U}$ and $\mathrm{Np}$, are caused by something other than different polytypes of the high-actinide phases. Other possible structural and microstructural factors influencing dissolution behavior may include defect-assisted dissolution related to the planar defects and dislocations in the U-bearing specimens, a composition-dependent dissolution rate for $\mathrm{C} 15 \mathrm{Fe}_{2} \mathrm{Zr}$, and differences in volume fractions and dissolution rates for the C15 and C36 $\mathrm{Fe}_{2} \mathrm{Zr}$ structures in the different samples.

\section{ACKNOWLEDGMENTS}

I thank Drs. Jan-Fong Jue, Tom O'Holleran, Wharton Sinkler, Dennis Keiser, and Steve Johnson, Mr. Mark Surchik, and Ms. Tanya Barber for their gracious assistance. This work was supported by the U.S. Department of Energy, Office of Nuclear Energy, Science and Technology, under Contract W-31-109-Eng-38 with the University of Chicago as operator of Argonne National Laboratory. 


\section{REFERENCES}

1. T. H. Bauer et al., "Modeling Corrosion and Constituent Release from a Metal Waste Form," Proceedings of the 9th International High-Level Radioactive Waste Management Conference, American Nuclear Society, Las Vegas, NV (April 29-May 3, 2001).

2. S. G. Johnson et al., "Release of Neptunium, Plutonium, Uranium, and Technetium from the Metallic Waste Form from the Electrometallurgical Treatment Process," MRS Symposium, Scientific Basis for Waste Management, Materials Research Society, Boston, MA (November 26-30, 2001).

3. S. G. Johnson et al., "Corrosion Characteristics of the Metal Waste Form from the Electrometallurgical Treatment Process: Technetium and Uranium Behavior During Long Term Immersion Tests,” Radioactive Waste Management and Environmental Restoration No. 4, 22:300-326 (2002).

4. D. D. Keiser Jr., D. P. Abraham, W. Sinkler, J. W. Richardson, Jr., and S. M. McDeavitt, "Actinide Distribution in a Stainless Steel-15 wt\% Zirconium High-Level Nuclear Waste Form,” Journal of Nuclear Materials, 279:234-244 (December 2000).

5. D. P. Abraham, J. W. Richardson, Jr., and S.M. McDeavitt, "Laves Intermetallics in Stainless Steel-Zirconium Alloys,” Materials Science and Engineering A: Structural Materials: Properties, Microstructure and Processing, 239-240:658-664 (December 1997).

6. D. P. Abraham, S. M. McDeavitt, and J. W. Richardson, Jr., "Laves Intermetallics in Stainless Steel-Zirconium Alloys,” 4th Conference on High Temperature Intermetallics, San Diego, CA (April 27-May 1, 1997).

7. D. P. Abraham and J.W. Richardson, Jr., "Phase Stability of Laves Intermetallics in a Stainless Steel-Zirconium Alloy," Long Term Stability of High Temperature Materials, ed. by G. E. Fuchs, K. A. Dannemann, and T. C. Deragon, TMS, Warrendale, PA. 169-179 (1999).

8. D. D. Keiser, Jr., D. P. Abraham, and J. W. Richardson, Jr., "Influence of Technetium on the Microstructure of a Stainless Steel-Zirconium Alloy,” Journal of Nuclear Materials, 277:333338 (February 2000).

9. X. Y. Meng and D. O. Northwood, "Polytype Structures in Zr-Cr-Fe Laves Phase,” Journal of the Less-Common Metals, 125:33-44 (1986).

10. C. W. Allen and K. C. Liao, “Dislocation Models for Shear Transformations,” Physica Status Solidi A, 74:673-681 (1982).

11. D. P. Abraham and N. Dietz, "Role of Laves Intermetallics in Nuclear Waste Disposal," Materials Science and Engineering A: Structural Materials: Properties, Microstructure and Processing, 329:610-615 (June 2002). 
12. P. Villers and L. D. Calvert, "Pearson's Handbook of Crystallographic Data for Intermetallic Phases Vol 3,” ASM International Database, Materials Park, OH (1991).

13. E. E. Havinga, H. Damsma, and P. Hokkeling, "Compounds and Pseudo-Binary Alloys with the $\mathrm{CuAl}_{2}$ (C16)-Type Structure,” Journal of the Less-Common Metals, 27:169-186 (1972).

14. K. H. J. Buschow, "Thermal Stability and Magnetic Properties of Amorphous $\mathrm{Zr}_{1-\mathrm{x}} \mathrm{Fe}_{\mathrm{X}}$ Alloys,” Journal of the Less-Common Metals, 79:243-253 (1981).

15. T. B. Massalski, ed., “Binary Alloy Phase Diagrams,” ASM International database (1990).

16. J. I. Goldstein, D. B. Williams, and G. Cliff, "Quantitative X-ray Analysis,” Principles of Analytical Electron Microscopy, D. C. Joy, A. D. Romig, Jr., and J. I. Goldstein, ed., 1 Plenum, New York, NY, 55-217 (1986).

17. S. M. McDeavitt, D. P. Abraham, and J. Y. Park, "Evaluation of Stainless Steel-Zirconium Alloys as High-Level Nuclear Waste Forms,” Journal of Nuclear Materials, 257:21-34 (September 1998).

18. Y. Liu, S. M. Allen, and J. D. Livingson, "An Investigation of $\mathrm{Fe}_{3} \mathrm{Zr}$ Phase," Scripta Metallurgica et Materialia, 32(8):1129-1132 (April 1995).

19. C. Servant, C. Gueneau, and I. Ansara, "Experimental and Thermodynamic Assessment of the Fe-Zr System,” Journal of Alloys and Compounds, 220(1-2):19-26 (April 1995).

20. D. P. Abraham, J. W. Richardson, Jr., and S. M. McDeavitt, "Formation of the $\mathrm{F}_{23} \mathrm{Zr}_{6}$ Phase in an Fe-Zr Alloy,” Scripta Materiala, 37(2):239-244 (July 1997).

21. H. Okamoto, "Fe-Pu (Iron-Plutonium)”, Phase Diagrams of Binary Actinide Alloys, ASM International, ed. by M. E. Kassner and D. E. Peterson, Materials Park, OH 314-317 (1995).

22. M. S. Granovsky and D. Arias, "Intermetallic Phases in the Iron-Rich Region of the Zr-Fe Phase Diagram,” Journal of Nuclear Materials, 229:29-35 (1996).

23. M. O’Keefe and B. G. Hyde, "Crystal Structures I. Patterns and Symmetry,” Mineralogical Society of America Monographs, Mineralogical Society of America, P. H Ribbe ed., Washington D.C. (1996).

24. C. S. Barrett and T. B. Massalski, Structure of Metals, McGraw-Hill, New York, NY (1966).

25. Y. Liu, J. D. Livingson, and S. M. Allen, "Room-Temperature Deformation and StressInduced Phase Transformation of Laves Phases in Fe-10 at. pct. Zr Alloy,” Metallurgical Transactions A, 23A:3303-3308 (December 1992).

26. J. P. Hirth and J. Lothe, Theory of Dislocations, Krieger Publishing Co., Malabar, FL (1992). 
27. R. E. Reed-Hill, Physical Metallurgy Principles, PWS-Kent Publishing Co., Boston, MA (1973).

28. R. E. Smallman, Modern Physical Metallurgy, Butterworths Publishing Co., London, England (1985).

29. S. M. McDeavitt, et al., "Stainless Steel-Zirconium Waste Forms from the Treatment of Spent Nuclear Fuel,” JOM, 49(7):29-32 (July 1997). 